\title{
Exploring the Role of Pendant Amines in Transition Metal Complexes for the Reduction of $\mathrm{N}_{2}$ to Hydrazine and Ammonia
}

\author{
Papri Bhattacharya, Demyan E. Prokopchuk, and Michael T. Mock* \\ Center for Molecular Electrocatalysis, Pacific Northwest National Laboratory, Richland, \\ Washington 99352, United States
}

Keywords: dinitrogen, ammonia, hydrazine, phosphines, pendant amine, chromium, molybdenum, tungsten, iron, vanadium

\begin{abstract}
This review examines the synthesis, properties, and acid reactivity of transition metal dinitrogen complexes bearing phosphine ligands containing pendant amine groups in the second coordination sphere. We have synthesized non-precious metal dinitrogen complexes containing bidentate, tridentate, and tetradentate phosphine ligands, some of which generate $\mathrm{N}_{2}$ derived
\end{abstract}


ammonia and/or hydrazine in the presence of excess acid. The metal identity, metal oxidation state, ligand denticity, and functional groups on phosphorus/nitrogen all play a role in controlling the site of protonation (at the metal, pendant amine, or coordinated dinitrogen) with the addition of exogenous acid.

\section{Introduction}

Humans are experts in the controlled release of energy from non-renewable carbon-based resources [1]. In contrast, combining protons and electrons together in an environmentally responsible manner to generate "on-demand" fuels is not widely utilized. In order to avoid exacerbating the effects already observed as a result of climate change, an important criterion of responsible fuel consumption would be to use renewable and abundant fuel sources while selecting abundant materials and elements to catalyze their production [2]. One fuel candidate that meets these requirements is ammonia $\left(\mathrm{NH}_{3}\right)$ [3-5], which could be produced directly from dinitrogen $\left(\mathrm{N}_{2}\right)$ (eq 1), or first to hydrazine $\left(\mathrm{N}_{2} \mathrm{H}_{4}\right)$ and then ammonia $\left(\mathrm{NH}_{3}\right)$ (eq 2 and 3 ) in the presence of protons, electrons, and a catalyst:

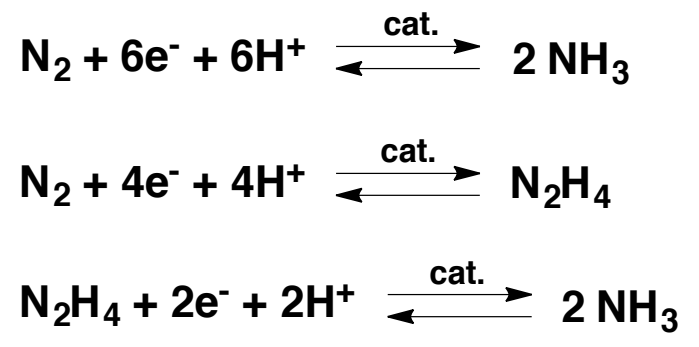

To further fulfill the requirements of using renewable and abundant resources for these transformations, the proton and electron source for the forward reaction can be dihydrogen $\left(\mathrm{H}_{2}\right)$ 
ultimately derived from water [6] $\left(\mathrm{H}_{2} \mathrm{O}\right)$ and the catalyst should contain abundant metal(s) (Ti, V, $\mathrm{Cr}, \mathrm{Mo}, \mathrm{W}, \mathrm{Mn}, \mathrm{Fe}, \mathrm{Co}, \mathrm{Ni})$, ideally coupled with solar energy to drive these reactions [7, 8].

The approach described above to reduce $\mathrm{N}_{2}$ mimics the process nitrogenase enzymes use to convert dinitrogen to ammonia, which sequentially add protons and electrons to a multi-metallic cofactor containing non-precious metals (Fe, Mo, V) under ambient conditions [9-13]. In stark contrast, current industrial standards rely on modern variants of the century old Haber-Bosch process to convert $\mathrm{N}_{2}$ to $\mathrm{NH}_{3}$, which requires high $\mathrm{H}_{2}$ pressures (150-350 atm) and temperatures $\left(350-550{ }^{\circ} \mathrm{C}\right)$, using solid supported Fe catalysts [14]. This results in an overall high energy consumption, and operates by a different $\mathrm{N}_{2}$ reduction mechanism under these demanding reaction conditions $[15,16]$.

In the last decade, diphosphine ligands containing non-coordinating pendant amines in the second coordination sphere have received considerable attention due to their ability to enhance the performance of molecular electrocatalysts [17]. The inclusion of pendant amines is inspired by naturally occurring catalysts such as [FeFe]-hydrogenase, whose non-coordinating pendant amine functions as a proton relay during catalysis [18]. For example, in the development of nickel-based bis(diphosphine) electrocatalysts for the oxidation of hydrogen, DuBois and coworkers found that utilizing the $\mathrm{P}^{\mathrm{R}} \mathrm{N}^{\mathrm{R}^{\prime}} \mathrm{P}^{\mathrm{R}}$ ligand platform $\left(\mathrm{P}^{\mathrm{R}} \mathrm{N}^{\mathrm{R}} \mathrm{P}^{\mathrm{R}}=\mathrm{R}_{2} \mathrm{PCH}_{2} \mathrm{~N}\left(\mathrm{R}^{\prime}\right) \mathrm{CH}_{2} \mathrm{PR}_{2}\right)$ in $\left[\mathrm{Ni}\left(\mathrm{P}^{\mathrm{Et}} \mathrm{N}^{\mathrm{Me}} \mathrm{P}^{\mathrm{Et}}\right)_{2}\right]^{2+}$ resulted in a $0.70 \mathrm{~V}$ decrease in the overpotential compared to a $\mathrm{Ni}$ complex bearing two diphosphine ligands without pendant amine groups such as $\left[\mathrm{Ni}(\mathrm{depp})_{2}\right]^{2+}(\operatorname{depp}=$ $\left.\mathrm{Et}_{2} \mathrm{PCH}_{2} \mathrm{CH}_{2} \mathrm{CH}_{2} \mathrm{PEt}_{2}\right)$ [19]. Furthermore, employing the $\mathrm{P}_{2} \mathrm{~N}^{\mathrm{R}_{2}^{\prime}}$ ligand $\left(\mathrm{P}_{2} \mathrm{~N}^{\mathrm{R}_{2}^{\prime}}=\right.$ substituted 1,5-diaza-3,7-diphosphacyclooctanes), containing a bio-inspired positioned pendant amine [20, 21] i.e. $\left[\mathrm{Ni}\left(\mathrm{P}^{\mathrm{Cy}}{ }_{2} \mathrm{~N}^{t B u}\right)_{2}\right)^{2+}$ afforded a 100 -fold enhancement in catalytic rate [17]. 
Building on the concept of second coordination sphere effects to control proton movement, we are interested in understanding whether diphosphines containing pendant amines can facilitate proton movement in the electrocatalytic conversion of dinitrogen to ammonia under mild conditions. To date, there are few known homogeneous transition metal complexes that catalyze the conversion of $\mathrm{N}_{2}$ to $\mathrm{NH}_{3}$ [22-27] and there are many reports that give a broad overview of recent developments in the field of $\mathrm{N}_{2}$ reduction chemistry, which go beyond the scope of this review [28-34]. Instead, we will highlight the progress made in our lab toward the synthesis and reactivity of dinitrogen complexes containing diphosphine ligands with pendant amines in the second coordination sphere. In particular, we have examined $\mathrm{Cr}, \mathrm{Mo}, \mathrm{W}, \mathrm{Fe}$ and $\mathrm{V}$ complexes, and will emphasize the effects of pendant amines on the reactivity with protons and/ or electrons.

\section{Chromium $\mathrm{N}_{2}$ complexes}

The synthesis and acid reactivity of low-valent mono- or bis(dinitrogen) complexes of Mo and $\mathrm{W}$ supported by monodentate, bidentate, or tridentate phosphine ligands have been rigorously examined over the last four decades [35-39]. In contrast, the chemistry of $\mathrm{Cr}-\mathrm{N}_{2}$ complexes of this structure type is remarkably undeveloped. Contributing to limited progress in this area is the scarcity of $\mathrm{Cr}-\mathrm{N}_{2}$ complexes, perhaps due to limited success obtaining stable $\mathrm{Cr}$ complexes with terminally bound $\mathrm{N}_{2}$ ligands [40-42]. Prior to our contributions with $\mathrm{Cr}$, to the best of our knowledge, there were only two reported $\mathrm{Cr}$ complexes supported by phosphine ligands with terminally bound $\mathrm{N}_{2}$ ligands, i.e. cis- $\left[\mathrm{Cr}\left(\mathrm{N}_{2}\right)_{2}\left(\mathrm{PMe}_{3}\right)_{4}\right]$ [43] and trans[Cr( $\left.\left(\mathrm{N}_{2}\right)_{2}(\mathrm{dmpe})_{2}\right]$ [44-46]. Given that $\mathrm{N}_{2}$ appears to interact differently with $\mathrm{Cr}$ as compared to 
Mo and W counterparts, we reasoned that if $\mathrm{N}_{2}$ coordination could be achieved, the resulting $\mathrm{Cr}$ $\mathrm{N}_{2}$ complexes might also exhibit atypical $\mathrm{N}_{2}$ reactivity patterns with acid. Furthermore, we were interested in understanding if pendant amines influenced the stability of $\mathrm{N}_{2}$ binding in these uncommon Cr systems. Our studies described below were initiated with the synthesis of a $\mathrm{Cr}-\mathrm{N}_{2}$ complex containing the cyclic 8-membered $\mathrm{P}^{\mathrm{Ph}}{ }_{2} \mathrm{~N}^{\mathrm{Bn}}$ ligand and were followed by studies of $\mathrm{Cr}$ $\mathrm{N}_{2}$ complexes containing novel tridentate and tetradentate phosphine ligands.

\section{1 $\mathrm{Cr}-\mathrm{N}_{2}$ complexes with the $\mathrm{P}_{2}{ }_{2} \mathrm{~N}_{2}$ ligand}

Entry into Cr chemistry with the $\mathrm{P}_{2}{ }_{2} \mathrm{~N}^{\mathrm{Bn}}$ ligand begins with the reaction of $\mathrm{CrCl}_{3}(\mathrm{THF})_{3}$ and 1 equiv of the diphosphine, affording the distorted octahedral complex $\left(\kappa^{3}-\mathrm{P}^{\mathrm{Ph}_{2}} \mathrm{~N}^{\mathrm{Bn}_{2}}\right) \mathrm{CrCl}_{3}(\mathbf{1})$. In addition to the phosphorus atoms, a pendant amine substituent is coordinated to $\mathrm{Cr},(\mathrm{Cr}-\mathrm{N}=$ 2.206(2) Å) which was the first structurally characterized example of a $\mathrm{K}^{3}$ binding mode in the $\mathrm{P}_{2} \mathrm{~N}^{\prime}{ }_{2}^{\prime}$ class of ligands [47]. Since this initial report, other examples of pendant aminecontaining diphosphine ligands (i.e. $\mathrm{P}^{\mathrm{R}} \mathrm{N}^{\mathrm{R}} \mathrm{P}^{\mathrm{R}}$ and $\mathrm{P}^{\mathrm{Ph}_{2}} \mathrm{~N}^{\mathrm{Bn}}$ ) have been structurally characterized revealing a $\kappa^{3}$-coordinate mode, including complexes of Mn [48] and Mo [49]. Employing 1 as synthon, treatment with $\mathrm{Mg}$ powder in THF in the presence of 1 equiv of $\mathrm{P}^{\mathrm{Ph}_{2} \mathrm{~N}^{\mathrm{Bn}}}$ for $18 \mathrm{~h}$, afforded cis-[Cr( $\left.\left.\mathrm{N}_{2}\right)_{2}\left(\mathrm{P}_{2} \mathrm{Ph}_{2}{ }_{2}\right)_{2}\right]$ (2) in a reproducible but low (ca. $15 \%$ ) yield (Scheme 1). At the time of this report, this was only the second example of a "Chatt-type" $\left((\mathrm{P}-\mathrm{P})_{2} \mathrm{M}\left(\mathrm{N}_{2}\right)_{2}, \mathrm{P}-\mathrm{P}=\right.$ diphosphine ligand.) 


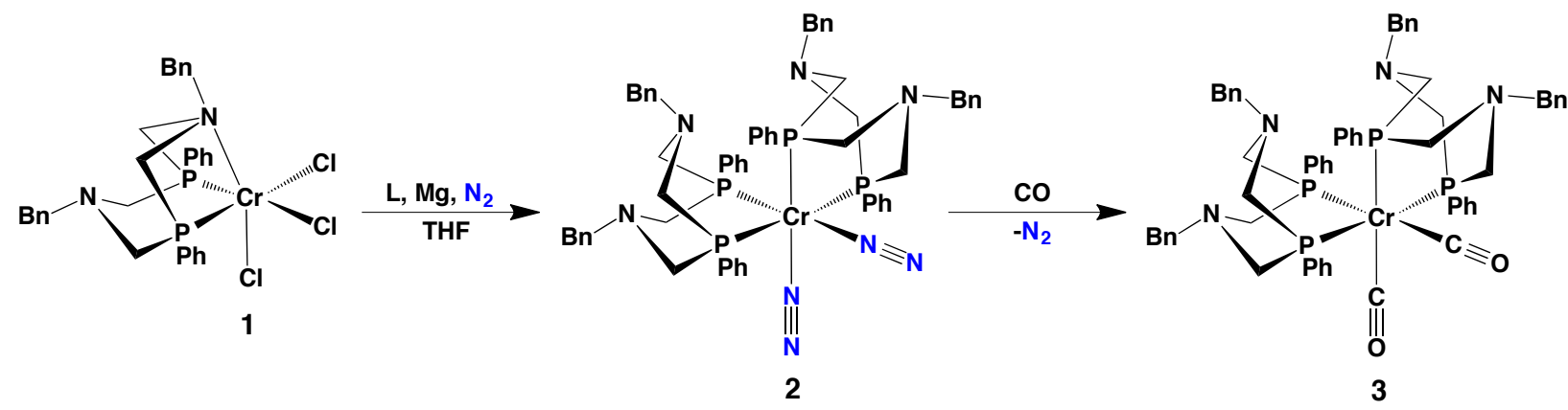

Scheme 1. Mg reduction of $\mathbf{1}$ in THF to form 2. Treatment of $\mathbf{2}$ with $\mathrm{CO}$ affords $\mathbf{3}$. $\mathrm{L}=\mathrm{P}_{2} \mathrm{Nh}_{2}$ ligand [47].

$\mathrm{Cr}-\mathrm{N}_{2}$ complex containing terminally bound $\mathrm{N}_{2}$ ligands that was stable toward $\mathrm{N}_{2}$ loss at room temperature. The infrared spectrum contained two $v_{\mathrm{NN}}$ bands at 2009 and $1937 \mathrm{~cm}^{-1}$ that shift to 1942 and $1873 \mathrm{~cm}^{-1}$, respectively, when prepared under ${ }^{15} \mathrm{~N}_{2}$ gas. The complex cis$\left[\mathrm{Cr}\left({ }^{15} \mathrm{~N}_{2}\right)_{2}\left(\mathrm{PPh}_{2} \mathrm{~N}^{\mathrm{Bn}}\right)_{2}\right]\left(\mathbf{2}^{15 N}\right)$ was characterized by ${ }^{15} \mathrm{~N}$ NMR spectroscopy, affording a doublet at $\delta-2.4$ and a broad resonance at $\delta-13.4$ for the distal and proximal nitrogen atoms of the $\mathrm{N}_{2}$ ligands, respectively [50]. Additionally, the cyclic voltammetry revealed an irreversible wave (at all scan rates up to $5 \mathrm{~V} / \mathrm{s}$ ) corresponding to the $\mathrm{Cr}^{\mathrm{I} / 0}$ couple at $-1.11 \mathrm{~V}$ (versus $\mathrm{Cp}_{2} \mathrm{Fe}^{+/ 0}$ ), suggesting the oxidized complex cis- $\left[\mathrm{Cr}\left(\mathrm{N}_{2}\right)_{2}\left(\mathrm{P}^{\mathrm{Ph}_{2} \mathrm{~N}^{\mathrm{Bn}}}\right)_{2}\right]^{+}$is unstable, likely due to $\mathrm{N}_{2}$ loss upon Cr oxidation. Treatment of a THF solution of $\mathbf{2}$ with $\mathrm{CO}$ afforded $c i s-\left[\mathrm{Cr}(\mathrm{CO})_{2}\left(\mathrm{P}_{2} \mathrm{Ph}_{2} \mathrm{~N}_{2}\right)_{2}\right](3)$, which exhibits two $v_{\mathrm{CO}}$ bands at 1837 and $1777 \mathrm{~cm}^{-1}$ [47]. The molecular structures of $\mathbf{2}$ and $\mathbf{3}$, shown in Fig. 1, are nearly identical, revealing the cis stereochemisty of the $\mathrm{N}_{2}$ and CO ligands. Complex 2 exhibits an N-N bond distance of 1.133(3) $\AA$, which is slightly elongated upon binding to $\mathrm{Cr}$ compared to free $\mathrm{N}_{2}$ at $1.0975 \AA$. 

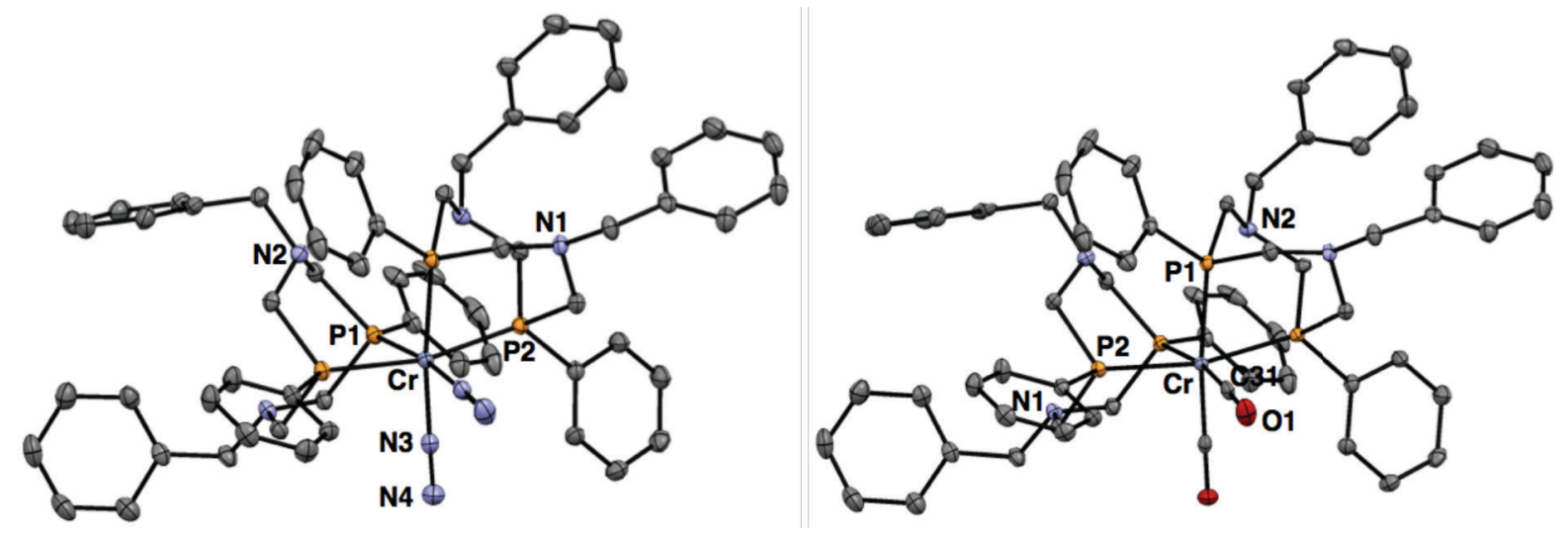

Fig. 1. Molecular structures of 2 (left) and 3 (right). Thermal ellipsoids drawn at $30 \%$ probability. Symmetry equivalent atom labels are not shown. Hydrogen atoms are omitted for clarity [47].

While reduction of $\mathbf{1}$ with $\mathrm{Mg}$ powder afforded only the cis-dinitrogen complex $\mathbf{2}$, reduction with potassium graphite $\left(\mathrm{KC}_{8}\right)$ generates a mixture of $\mathbf{2}$ and trans- $\left[\mathrm{Cr}\left(\mathrm{N}_{2}\right)_{2}\left(\mathrm{P}^{\mathrm{Ph}_{2}} \mathrm{~N}^{\mathrm{Bn}_{2}}\right)_{2}\right]$ (trans-2) in a reaction that was complete in $4 \mathrm{~h}$ (Scheme 2).

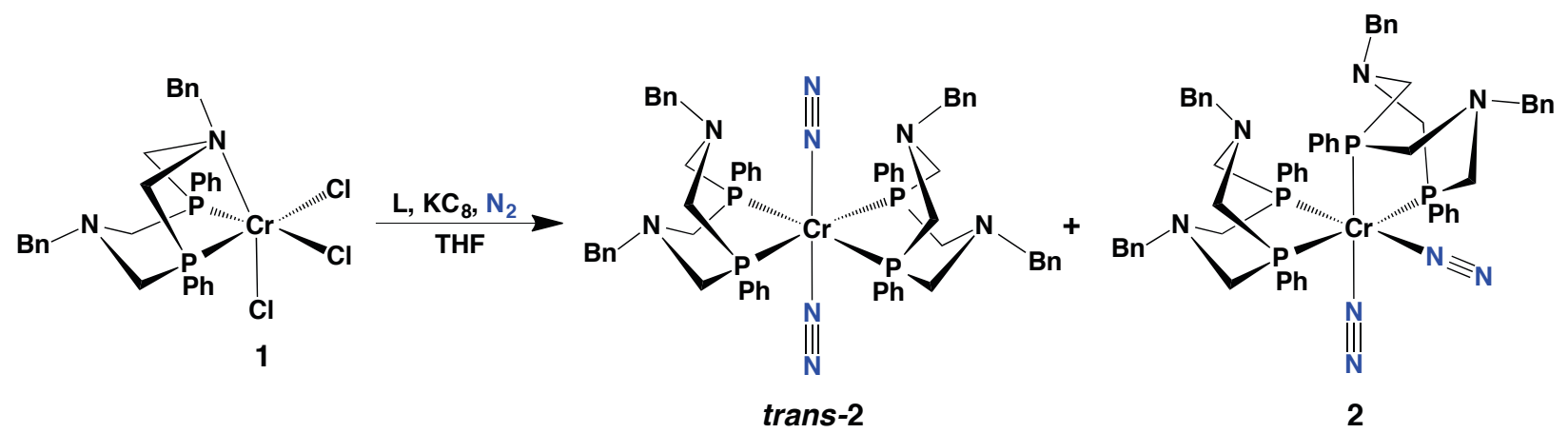

Scheme 2. Formation of 2 and trans-2 by $\mathrm{KC}_{8}$ reduction in THF. $\mathrm{L}=\mathrm{P}^{\mathrm{Ph}_{2}} \mathrm{NBn}_{2}$ ligand [47].

The IR spectrum of trans-2 exhibits a single $v_{\mathrm{NN}}$ band at $2007 \mathrm{~cm}^{-1}$ (hexanes), shifting to 1941 $\mathrm{cm}^{-1}$ when prepared under an atmosphere of ${ }^{15} \mathrm{~N}_{2}$ gas. The exact reason for the difference in cis and trans product formation based on the reductant identity is unclear. One possible cause for the contrasting product distribution is the more rapid reduction rate with $\mathrm{KC}_{8}$, which may favor the 
formation of the trans isomer as the kinetic product. Isomerization to the cis isomer may slowly occur over the longer reduction times required with Mg powder. The trans isomer was unstable over the course of several days in solution at room temperature, in contrast to the cis isomer that was stable for weeks in solution [47].

Computational analysis was employed to corroborate the observed difference in stability of the 2 and trans-2 isomers and to examine the nature of the $\mathrm{Cr}-\mathrm{N}_{2}$ interaction [47]. These studies suggested the $\mathrm{Cr}-\mathrm{N}_{2}$ interaction is best described by strong electronic polarization of the $\mathrm{N}_{2}$ ligands by the large amount of negative charge buildup at the $\mathrm{Cr}$ center, as NBO analysis found virtually no net metal-to-ligand charge transfer to $\mathrm{N}_{2}$. Based on this electrostatic interpretation of the $\mathrm{Cr}-\mathrm{N}_{2}$ bonding, the pendant amine groups were found to play a decisive role in the stability of the cis and trans isomers. Specifically, the $\mathrm{N}_{2} \cdots$ pendant amine interactions were found to be repulsive; therefore, close interactions of the pendant amines destabilize $\mathrm{N}_{2}$ binding by depolarizing the $\mathrm{N}_{2}$ ligands. For this reason, the cis isomer was predicted by DFT to be lowest in energy and the thermodynamically preferred geometric isomer because the boatchair conformation of the $\mathrm{P}_{2} \mathrm{~N}^{\mathrm{Bn}}$ ligand in a cis configuration minimizes direct interactions of the pendant amine groups with the $\mathrm{N}_{2}$ ligands. In contrast, the boat-chair conformation of the $\mathrm{P}_{2} \mathrm{~N}^{\mathrm{Bn}}{ }_{2}$ ligand for the trans isomer results in at least one interaction of the pendant amine groups with the $\mathrm{N}_{2}$ ligands, making it less stable by up to $6 \mathrm{kcal} \mathrm{mol}^{-1}$.

\subsection{Chromium complexes containing $\mathrm{P}^{\mathrm{Ph}}{ }_{3} \mathrm{~N}^{\mathrm{Bn}}{ }_{3}$ and $\mathrm{P}^{\mathrm{Ph}}{ }_{4} \mathrm{~N}^{\mathrm{Bn}}{ }_{4}$ ligands}

The low yield of $\mathbf{2}$ when prepared by the Mg reduction of $\mathbf{1}$ motivated us to explore other potential $\mathrm{Cr}$ precursors to prepare $\mathbf{2}$ in a greater yield. The synthesis of the complex $\mathrm{CrCl}_{2}\left(\mathrm{P}_{2} \mathrm{PH}_{2} \mathrm{Nn}_{2}\right.$ was considered an appropriate target as dihalide precursors such as 
$\mathrm{CrCl}_{2}(\mathrm{dmpe})_{2}$ [51] and $\mathrm{CrCl}_{2}(\mathrm{depe})_{2}$ [52] have been reported by the addition of $\mathrm{CrCl}_{2}$ (THF) and the 2 equiv of the appropriate diphosphine ligand. Following an analogous procedure, the addition of $\mathrm{CrCl}_{2}$ (THF) to a stirring THF solution containing 2 equiv of $\mathrm{PPh}_{2} \mathrm{~N}^{\mathrm{Bn}}{ }_{2}$ resulted in a bright green solution which slowly turned brown after stirring for several hours. The desired $\mathrm{CrCl}_{2}\left(\mathrm{P}_{2}{ }_{2} \mathrm{~N}^{\mathrm{Bn}}{ }_{2}\right)_{2}$ complex was never isolated from this reaction; instead, two Cr-containing products containing larger phosphorus macrocycle ligands were formed (Fig. 2) [53]. X-ray crystallographic analysis identified yellow crystals (isolated in $5 \%$ yield) as the $\mathrm{Cr}^{\mathrm{II}}$ complex trans- $\left[\mathrm{CrCl}_{2}\left(\mathrm{PPh}_{4} \mathrm{~N}^{\mathrm{Bn}} 4\right)\right]$ (4) that contained a 16-membered phosphorus macrocycle. Additionally, dark blue crystals were identified as the $\mathrm{Cr}$ III complex $\left(\mathrm{P}^{\mathrm{Ph}}{ }_{3} \mathrm{~N}_{3}\right) \mathrm{CrCl}_{3}(\mathbf{5}) 25 \%$ yield, bearing a smaller facially coordinating 12-membered phosphorus macrocycle.

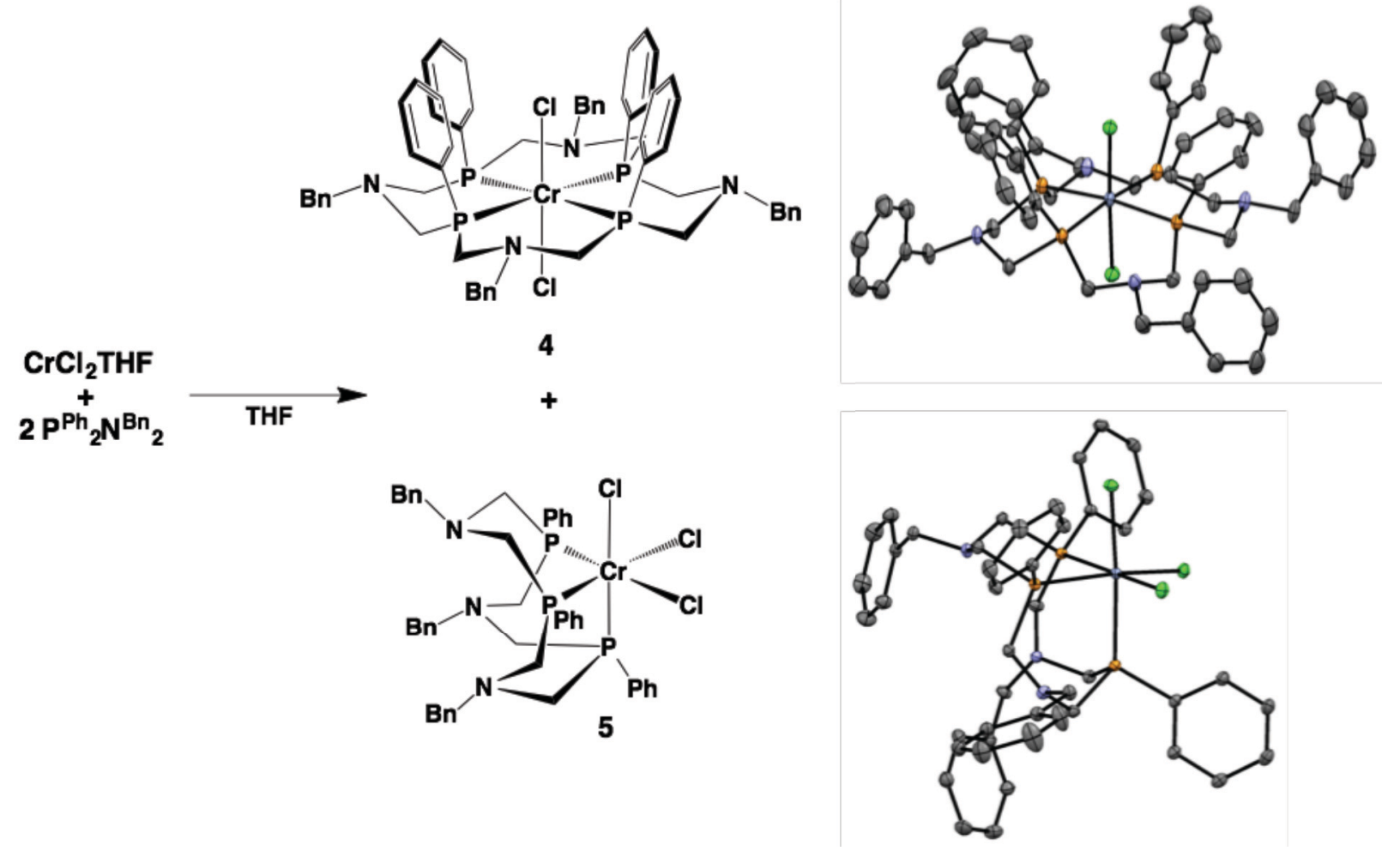

Fig. 2. Formation of [12]- $\mathrm{P}^{\mathrm{Ph}_{3}} \mathrm{~N}^{\mathrm{Bn}}{ }_{3}$ and [16]- $\mathrm{PPh}_{4} \mathrm{~N}^{\mathrm{Bn}} 4$ ligands isolated on $\mathrm{Cr}$ (complexes 4 and 5). Thermal ellipsoids drawn at $30 \%$ probability. Hydrogen atoms are omitted for clarity [53]. 
The 12- and 16-membered macrocycle ligands were isolated as the $\mathrm{Cr}$ coordination complexes, and have not been isolated independently as free ligands. The mechanism leading to the formation of the larger $\mathrm{P}-\mathrm{N}$ macrocycles starting from the $\mathrm{Cr}^{\mathrm{II}}$ salt remains unclear, however these novel 12-and 16-membered ligands were utilized to prepare the desired $\mathrm{Cr}-\mathrm{N}_{2}$ complexes.

Complex 4 was reduced in THF with Mg powder to yield the bis(dinitrogen) complex

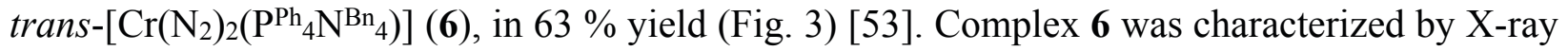
crystallography revealing the trans-disposed $\mathrm{N}_{2}$ ligands bound to $\mathrm{Cr}$. The $\mathrm{N}_{2}$ ligand residing within the pocket of four electron-rich phenyl groups exhibits a $\mathrm{Cr}-\mathrm{N}$ bond length of 1.930(2) $\AA$. The opposing $\mathrm{N}_{2}$ ligand outside the phenyl pocket has a shorter $\mathrm{Cr}-\mathrm{N}$ bond length of 1.884(2) $\AA$.
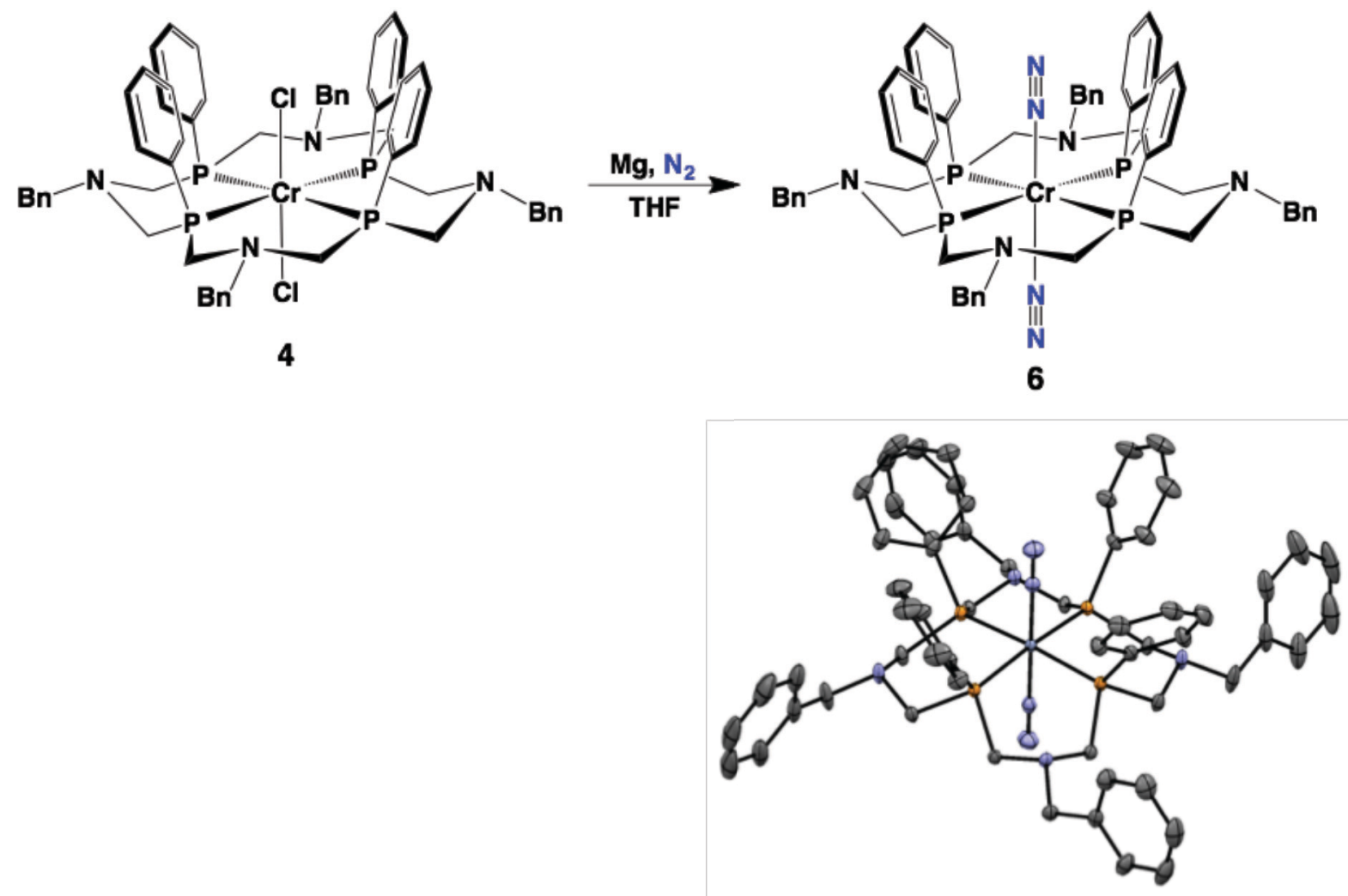
Fig. 3. $\mathrm{Mg}$ reduction of 4 to form the Cr-dinitrogen complex 6. Thermal ellipsoids drawn at 30\% probability. Hydrogen atoms are omitted for clarity [53].

In accord with the observed variance of $\mathrm{Cr}-\mathrm{N}$ bond distances, DFT calculations predicted the environment of the phenyl pocket destabilizes the $\mathrm{Cr}-\mathrm{N}$ binding energy by $7 \mathrm{kcal} / \mathrm{mol}$ compared to that of the opposing $\mathrm{N}_{2}$ ligand. The $\mathrm{N}-\mathrm{N}$ bond distance of the $\mathrm{N}_{2}$ ligand residing in the pocket is $1.112(3) \AA$, while the opposing $\mathrm{N}_{2}$ ligand $\mathrm{N}-\mathrm{N}$ distance is $1.120(3) \AA$. The IR spectrum recorded in THF indicates that the $\mathrm{N}_{2}$ ligands are moderately activated as a strong $v_{\mathrm{NN}}$ band was observed at $1918 \mathrm{~cm}^{-1}$ and a weak intensity band at $2072 \mathrm{~cm}^{-1}$ for the antisymmetric and symmetric $\mathrm{N}_{2}$ stretching modes. The assignment of the $v_{\mathrm{NN}}$ bands was further corroborated by the Raman spectrum of a microcrystalline sample of $\mathbf{6}$. Furthermore, the cyclic voltammogram of 6 in THF at a scan rate of $0.1 \mathrm{~V} / \mathrm{s}$ displays an irreversible $\mathrm{Cr}^{\mathrm{I} / 0}$ wave at $E_{\mathrm{pa}}=-1.18 \mathrm{~V}$, which became quasi-reversible at faster scan rates (ca. $5 \mathrm{~V} / \mathrm{s}$ ) [53].

Protonation studies with triflic acid (HOTf) were carried out at $-50{ }^{\circ} \mathrm{C}$ with samples of 6 prepared with ${ }^{15} \mathrm{~N}_{2}$ gas so the reaction could be followed by ${ }^{15} \mathrm{~N}$ NMR spectroscopy [53]. Acid addition at low temperature was necessary as immediate bleaching of the orange solution occurred at room temperature due to $\mathrm{N}_{2}$ dissociation from $\mathrm{Cr}$. Treatment of $\mathbf{6}$ with 3 equiv of HOTf initially formed products containing protonated pendant amine groups such as 7, shown in Scheme 3, that were assigned on the basis of ${ }^{31} \mathrm{P}$ and ${ }^{15} \mathrm{~N}$ NMR spectroscopic data. In addition, a cross peak observed in a ${ }^{1} \mathrm{H}-{ }^{15} \mathrm{~N}$ HSQC experiment with a ${ }^{15} \mathrm{~N}$ signal at $-181.0 \mathrm{ppm}$ and a ${ }^{1} \mathrm{H}$ signal at $12.1 \mathrm{ppm}$ was tentatively assigned as a diazenido $(\mathrm{Cr}-\mathrm{N}-\mathrm{N}-\mathrm{H})$ species based on known ${ }^{15} \mathrm{~N}$ chemical shifts in this region of the NMR spectrum [54-56]. The reaction was kept at $-50{ }^{\circ} \mathrm{C}$ and hydrazinium $\left({ }^{15} \mathrm{~N}_{2} \mathrm{H}_{5}+\right)$ was first observed in the ${ }^{15} \mathrm{~N}$ NMR spectrum after $27 \mathrm{~h}$. 

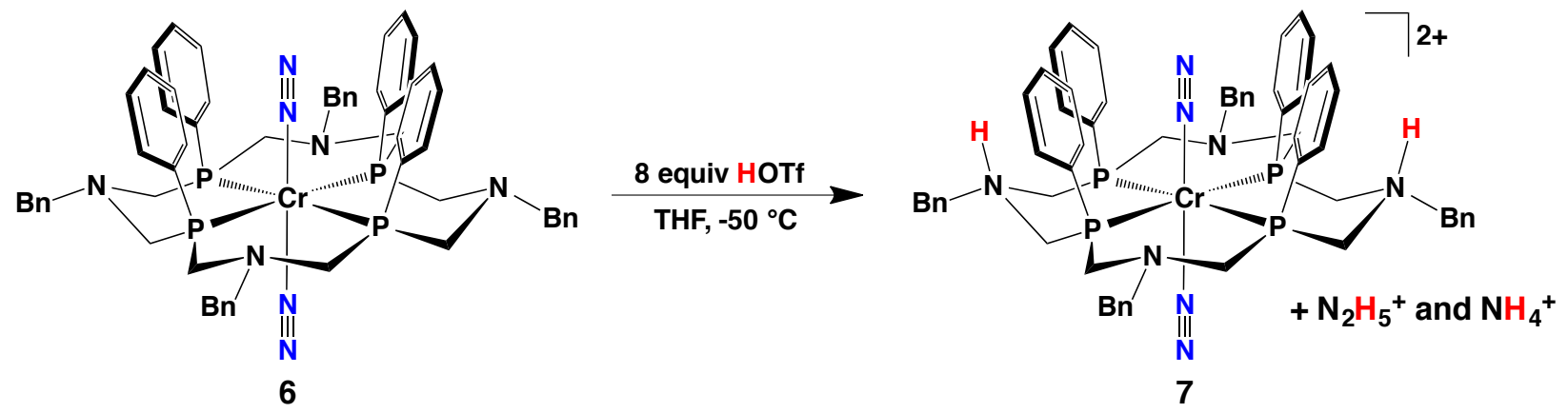

Scheme 3. Protonation of 6 affording 7, $\mathrm{N}_{2} \mathrm{H}_{5}{ }^{+}$, and $\mathrm{NH}_{4}{ }^{+}$from reduction of the $\mathrm{N}_{2}$ ligands. $\mathrm{N}_{2}$ ligands are derived from ${ }^{15} \mathrm{~N}_{2}[53]$.

Treatment with an additional 5 equiv of HOTf resulted in an increase of the ${ }^{15} \mathrm{~N}_{2} \mathrm{H}_{5}{ }^{+}$peak in the ${ }^{15} \mathrm{~N}$ NMR spectrum as well as the appearance of a new ${ }^{15} \mathrm{~N}$ resonance at $-364 \mathrm{ppm}$ corresponding to the formation of ammonium $\left({ }^{15} \mathrm{NH}_{4}^{+}\right)$in solution.

Computational studies were performed to examine the protonation mechanism leading to hydrazine formation [53]. DFT calculations predicted that protonation of the pendant amine groups lowers the dissociation energy of the $\mathrm{N}_{2}$ ligand residing in the pocket of the phenyl rings. The dissociation of one of the $\mathrm{N}_{2}$ ligands increases the proton affinity of the remaining $\mathrm{N}_{2}$ ligand by $12 \mathrm{kcal} / \mathrm{mol}$, thus $\mathrm{N}_{2}$ loss is a critical step to initiate the protonation of the coordinated $\mathrm{N}_{2}$ to form the diazenido species. Further DFT results suggested protonation of the diazenido ligand at the distal $\mathrm{N}$ atom to form a hydrazido $\left(\mathrm{Cr}-\mathrm{N}=\mathrm{NH}_{2}\right)$ intermediate was favored by $\sim 7.5 \mathrm{kcal} / \mathrm{mol}$ over protonation at the proximal $\mathrm{N}$ atom affording a diazene (Cr-NHNH) species; each occurring with a concomitant spin-state change of Cr from a singlet to a triplet. Notably, the DFT simulations also predicted a bent $\mathrm{Cr}$-hydrazido species $\left(\mathrm{Cr}-\mathrm{N}-\mathrm{N}=144^{\circ}\right)$ that contrasts the linear hydrazido structures typically found in Mo and W complexes due to the formation of 
metal-nitrogen multiple bonds. Subsequent protonation steps were envisaged to occur at the proximal $\mathrm{N}$ atom, and thus the lack of $\mathrm{Cr}-\mathrm{N}$ multiple bonding was implicated to be a principle factor leading to the formation of hydrazine as the predominant $\mathrm{N}_{2}$ reduction product.

Complex 5, bearing the facially coordinating [12]- $\mathrm{P}^{\mathrm{Ph}}{ }_{3} \mathrm{~N}^{\mathrm{Bn}}$ ligand, was reduced with $\mathrm{Mg}$ powder in the presence of 1 equiv dmpe $\left(\mathrm{dmpe}=\mathrm{Me}_{2} \mathrm{PCH}_{2} \mathrm{CH}_{2} \mathrm{PMe}_{2}\right)$ to form $\mathrm{Cr}\left(\mathrm{N}_{2}\right)(\mathrm{dmpe})$ $\left(\mathrm{P}_{3} \mathrm{~N}{ }^{\mathrm{Bn}} 3\right)(\mathbf{8})$ in $80 \%$ yield (Fig. 4) [57]. To the best of our knowledge, complex 8 was the first example of a mono-dintrogen complex of $\mathrm{Cr}$ in a pentaphosphorus coordination environment. The five phosphorus donors resulted in a very electron-rich $\mathrm{Cr}$ center, as supported by the $v_{\mathrm{NN}}$ band in the IR at $1918 \mathrm{~cm}^{-1}$ and the N-N bond distance of 1.132(3) $\AA$ as determined by X-ray crystallography. Notably, the $\mathrm{N}_{2}$ vibrational frequency of $\mathbf{8}$ is lower than similar Mo- $\mathrm{N}_{2}$ complexes with a pentaphosphorus coordination environment bearing only alkyl substituents on the phosphorus atoms. For example, Tuczek and co-workers prepared numerous examples of Mo mono-dinitrogen complexes [58-63] bearing a combination of tridentate and bidentate phosphine ligands; the complex $\mathrm{Mo}\left(\mathrm{N}_{2}\right)\left(\mathrm{SiP}^{\mathrm{Me}}{ }_{2} \mathrm{P}^{\mathrm{PPr}}\right)(\mathrm{dmpm})[63],\left(\mathrm{SiP}_{2} \mathrm{P}^{\mathrm{iPr}}=\right.$ [(diisopropylphosphino)methyl)-bis[(dimethylphosphino)methyl](methylsilane); dmpm = 


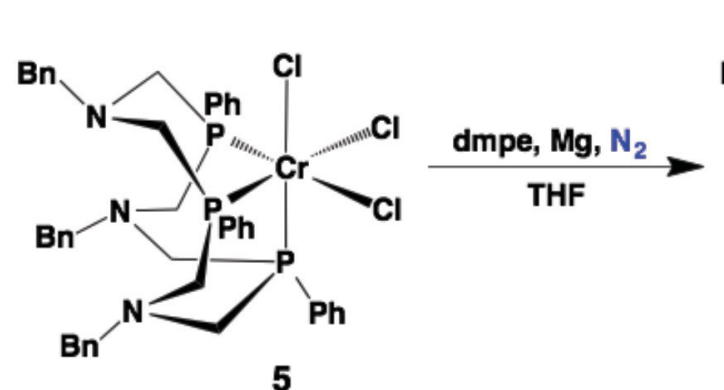

5

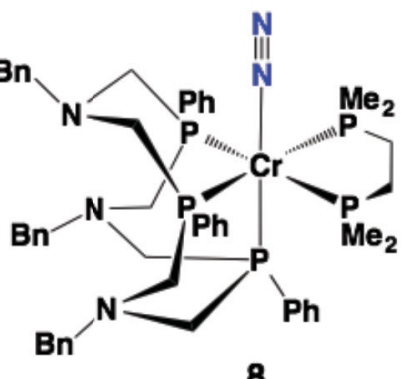

8

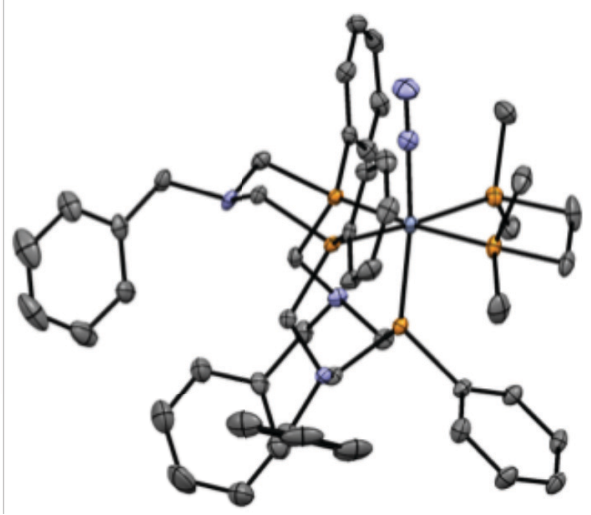

Fig. 4. The reduction of 5 with $\mathrm{Mg}$ in the presence of dmpe to form 8. Thermal ellipsoids drawn at $30 \%$ probability. Hydrogen atoms are omitted for clarity [57].

$\mathrm{Me}_{2} \mathrm{PCH}_{2} \mathrm{PMe}_{2}$ ) containing only alkyl substituted phosphines, exhibits the lowest $v_{\mathrm{NN}}$ band at $1932 \mathrm{~cm}^{-1}$. The lower $\mathrm{N}_{2}$ vibrational frequency for $\mathbf{8}$ is noteworthy given the expected periodic trend of increased basicity descending the group [64, 65]. Indeed, periodic trends influencing $\mathrm{N}_{2}$ vibrational frequencies and acid reactivity for all the group 6 metals are not clearly established, mainly due to the lack of comparable complexes bearing identical ligands. This is a subject we recently addressed in a study that examined an isostructural series of $\mathrm{Cr}, \mathrm{Mo}$, and $\mathrm{W}-\mathrm{N}_{2}$ complexes [66]. .

The cyclic voltammogram of $\mathbf{8}$ recorded in THF $(0.1 \mathrm{~V} / \mathrm{s})$ exhibits two one-electron redox processes [57]. The half-wave potential for the $\mathrm{Cr}^{\mathrm{I} / 0}$ couple appears as a reversible wave at $E_{1 / 2}=$ $-1.50 \mathrm{~V}$, and an irreversible $\mathrm{Cr}^{\mathrm{I} / /}$ oxidation wave appears at $E_{\mathrm{pa}}=-0.77 \mathrm{~V}$. The reversible $\mathrm{Cr}^{\mathrm{I} / 0}$ 
couple suggests that the $\mathrm{Cr}^{\mathrm{I}}-\mathrm{N}_{2}$ cation may exhibit modest stability in solution, however chemical oxidation was not investigated. Compared to $\mathbf{2}$ and $\mathbf{6}$, the pentaphosphine ligand environment of 8 displays a $\mathrm{Cr}^{\mathrm{I} / 0}$ oxidation wave that is $\sim 0.35 \mathrm{~V}$ more negative than the bis(dinitrogen) counterparts and likely helps stabilize the $\mathrm{Cr}^{\mathrm{I}}-\mathrm{N}_{2}$ complex from ligand loss upon metal oxidation.

The acid reactivity of $\mathbf{8}$ was examined at low temperature with both HOTf and $\left[\mathrm{H}\left(\mathrm{OEt}_{2}\right)_{2}\right]\left[\mathrm{B}\left(\mathrm{C}_{6} \mathrm{~F}_{5}\right)_{4}\right]$ [57]. Monitoring the reaction by in situ IR spectroscopy, treatment of $\mathbf{8}$ with 1 equiv of $\left[\mathrm{H}\left(\mathrm{OEt}_{2}\right)_{2}\right]\left[\mathrm{B}\left(\mathrm{C}_{6} \mathrm{~F}_{5}\right)_{4}\right]$ in THF at $-78{ }^{\circ} \mathrm{C}$ afforded a 7 -coordinate $\mathrm{Cr}^{-\mathrm{N}_{2}}$ hydride complex $\left[\mathrm{Cr}(\mathrm{H})\left(\mathrm{N}_{2}\right)(\mathrm{dmpe})\left(\mathrm{P}^{\mathrm{Ph}_{3} \mathrm{~N}^{\mathrm{Bn}}} 3\right)\right]^{+}$(9) (Scheme 4), based on a shift of the $v_{\mathrm{NN}}$ band from $1918 \mathrm{~cm}^{-1}$ to $2006 \mathrm{~cm}^{-1}$. Complex 9 was further characterized by variable-temperature ${ }^{31} \mathrm{P}$ NMR spectroscopy and ${ }^{15} \mathrm{~N}$ NMR spectroscopy in samples prepared using ${ }^{15} \mathrm{~N}_{2} .9$ was found to be thermally unstable and $\mathrm{N}_{2}$ loss occurred in solution at above $-30{ }^{\circ} \mathrm{C}$. To investigate the stoichiometric formation of $\mathrm{NH}_{3}$ and hydrazine, 12 equiv of HOTf was added to 8 (a sample prepared with ${ }^{15} \mathrm{~N}_{2}$ gas) at $-78{ }^{\circ} \mathrm{C}$ and the reaction monitored by ${ }^{15} \mathrm{~N}$ NMR spectroscopy. After 24 $\mathrm{h}$ at $-50{ }^{\circ} \mathrm{C}$, only a trace amount of ${ }^{15} \mathrm{NH}_{4}{ }^{+}$was formed, and ${ }^{15} \mathrm{~N}_{2} \mathrm{H}_{5}{ }^{+}$was not observed.

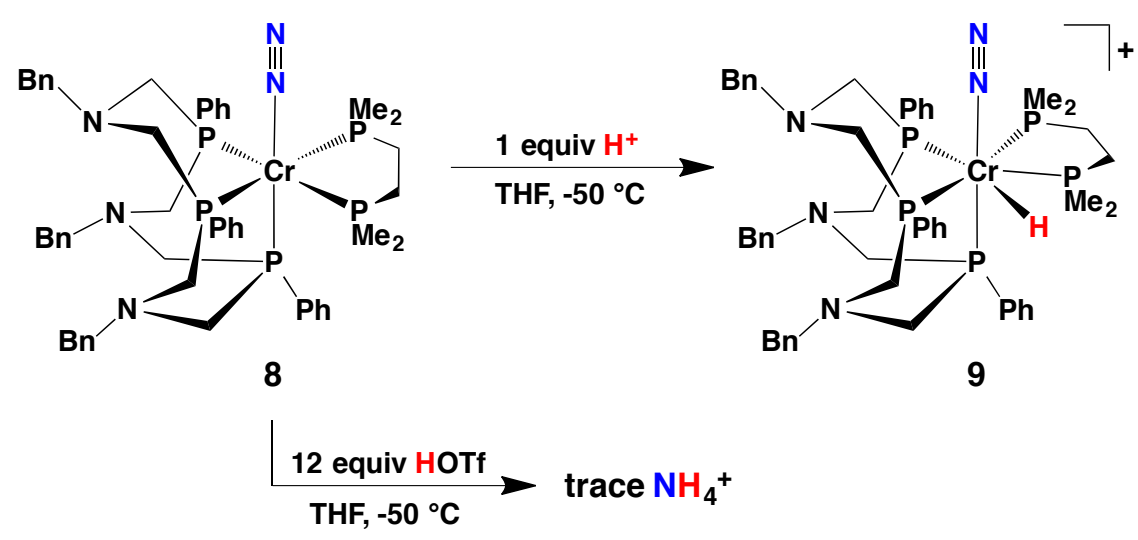


Scheme 4. Top: Protonation of $\mathbf{8}$ with 1 equiv acid to form 9. Bottom: reaction of $\mathbf{8}$ with excess acid forming a trace amount of $\mathrm{NH}_{4}{ }^{+} . \mathrm{N}_{2}$ ligands are derived from ${ }^{15} \mathrm{~N}_{2}$ gas. $\mathrm{H}^{+}=\left[\mathrm{H}\left(\mathrm{OEt}_{2}\right)_{2}\right]$ $\left[\mathrm{B}\left(\mathrm{C}_{6} \mathrm{~F}_{5}\right)_{4}\right]$.

In order to rationalize the acid reactivity of complexes $\mathbf{6}$ and $\mathbf{8}$ leading to the formation of ${ }^{15} \mathrm{~N}_{2}$ derived ${ }^{15} \mathrm{~N}_{2} \mathrm{H}_{5}{ }^{+}$and ${ }^{15} \mathrm{NH}_{4}{ }^{+}$products, a comprehensive computational study was employed [57]. The main differences in $\mathrm{N}_{2}$ reactivity predicted by DFT suggested that the electron-rich $\mathrm{Cr}$ center in $\mathbf{8}$ helps to stabilize $\mathrm{Cr}-\mathrm{N}_{\mathrm{x}} \mathrm{H}_{\mathrm{y}}$ intermediates that contain $\mathrm{Cr}-\mathrm{N}$ multiple bonds, such as a linear hydrazido species $\left(\mathrm{Cr}=\mathrm{N}=\mathrm{NH}_{2}\right)$. Thus, in contrast to the DFT results described above for $\mathbf{6}$, an "alternating" $\mathrm{N}_{2}$ reduction pathway would be favored to form $\mathrm{NH}_{3}$ over hydrazine in this case. However, due to the high basicity of $\mathrm{Cr}$, there is a strong thermodynamic preference to protonate the metal center, which is a competing reaction with $\mathrm{N}_{2}$ protonation.

\section{Molybdenum Complexes}

To catalyze the reduction of dinitrogen to ammonia, group 6 transition metal dinitrogen complexes, especially those of molybdenum, have been of greatest interest to many research groups, partly because Mo is present in the iron-molybdenum cofactor (FeMoco) in nitrogenase [12]. Despite an extensive effort over 40 years, there have been only a few examples of homogeneous systems of Mo, notably from the research groups of Schrock and Nishibayashi, which catalyze the reduction of dinitrogen to ammonia with protons and electrons $[22,23,27$, 67]. Given the well-documented acid reactivity patterns of $\mathrm{Mo}-\mathrm{N}_{2}$ complexes supported by traditional phosphine ligands, our efforts focused on designing Mo- $\mathrm{N}_{2}$ complexes with pendant amines in the secondary coordination sphere to assess the influence of the pendant bases on the 
acid reactivity patterns, and ultimately to develop electrocatalytic systems to carry out this multiproton, multi-electron transformation.

\subsection{Mo- $\mathrm{N}_{2}$ complexes with $\mathrm{P}^{\mathrm{R}} \mathrm{N}^{\mathrm{R}^{\prime}} \mathrm{P}^{\mathrm{R}}$ ligands}

In contrast to the coordination chemistry of the cyclic 8-membered $\mathrm{PPh}_{2} \mathrm{~N}^{\mathrm{Bn}} 2$ ligand described above with chromium (e.g. complexes 2 and trans-2), our efforts to prepare similar Mo (or W) dinitrogen complexes of the type cis- or trans-[Mo( $\left.\left(\mathrm{N}_{2}\right)_{2}\left(\mathrm{P}_{2}{ }_{2} \mathrm{~N}^{\prime}\right)_{2}\right]$ by following wellestablished synthetic procedures [68] that employed traditional diphosphine ligands were unsuccessful. Despite the challenges with the $\mathrm{P}_{2} \mathrm{~N}^{\prime}{ }_{2}$ class of ligands, we could readily synthesize a series of molybdenum bis(dinitrogen) complexes supported with two $\mathrm{P}^{R} \mathrm{~N}^{\mathrm{R}^{\prime}} \mathrm{P}^{\mathrm{R}}$ diphosphine ligands, $\mathrm{P}^{\mathrm{R}} \mathrm{N}^{\mathrm{R}^{\prime}} \mathrm{P}^{\mathrm{R}}=\left(\mathrm{R}_{2} \mathrm{PCH}_{2}\right)_{2} \mathrm{~N}\left(\mathrm{R}^{\prime}\right), \mathrm{R}=\mathrm{Et}, \mathrm{Ph} ; \mathrm{R}^{\prime}=\mathrm{Me}, \mathrm{Bn}$ [69]. The synthesis was carried out in a one pot procedure for the ligands with ethyl substituents on phosphorous $\mathrm{P}^{\mathrm{E}} \mathrm{N}^{\mathrm{R}} \mathrm{P}^{\mathrm{Et}}\left(\mathrm{R}^{\prime}=\mathrm{Me}, \mathrm{Bn}\right)$ by reduction of $\mathrm{MoBr}_{3}(\mathrm{THF})_{3}$ with $\mathrm{Mg}$ powder in the presence of 2 equiv $\mathrm{P}^{\mathrm{R}} \mathrm{N}^{\mathrm{R}} \mathrm{P}^{\mathrm{R}}$ (Scheme 5). The cis isomer, cis-[Mo( $\left.\left.\mathrm{N}_{2}\right)_{2}\left(\mathrm{P}^{\mathrm{E}} \mathrm{N}^{\mathrm{R}} \mathrm{P}^{\mathrm{Et}}\right)_{2}\right]\left(\mathrm{R}=\mathrm{Et}, \mathrm{R}^{\prime}=\mathrm{Bn}(\mathbf{1 0}) ; \mathrm{R}=\right.$ $\left.\mathrm{Et}, \mathrm{R}^{\prime}=\mathrm{Me}(\mathbf{1 1})\right)$ is the kinetic product of this reaction, and was isolated after $2.5 \mathrm{~h}$ of starting the reduction with only a minor amount of the trans isomer being formed after this time. Extended reaction stirring in THF for $48-60 \mathrm{~h}$ at room temperature resulted in the cis products isomerizing to $>85 \%$ yield of the trans isomer, trans- $\left[\mathrm{Mo}\left(\mathrm{N}_{2}\right)_{2}\left(\mathrm{P}^{\mathrm{E}} \mathrm{N}^{\mathrm{R}^{\prime}} \mathrm{P}^{\mathrm{Et}}\right)_{2}\right]\left(\mathrm{R}^{\prime}=\mathrm{Bn}(\mathbf{1 2}) ; \mathrm{R}^{\prime}=\right.$

Me (13). Alternatively, a stepwise reductive route could also be followed by first treating $\mathrm{MoBr}_{3}(\mathrm{THF})_{3}$ with $\mathrm{Zn}$ flakes in the presence of 2 equiv of $\mathrm{P}^{\mathrm{R}} \mathrm{N}^{\mathrm{R}^{\prime}} \mathrm{P}^{\mathrm{R}}$ ligand to afford $\operatorname{MoBr}_{2}\left(\mathrm{P}^{\mathrm{Ph}} \mathrm{N}^{\mathrm{R}^{\prime}} \mathrm{P}^{\mathrm{Ph}}\right)_{2}\left(\mathrm{R}^{\prime}=\mathrm{Bn}(\mathbf{1 4}) ; \mathrm{R}^{\prime}=\mathrm{Me}(\mathbf{1 5})\right.$. Reduction of 14 and 15 with $\mathrm{Mg}$ powder under $\mathrm{N}_{2}$ atmosphere formed trans-[Mo( $\left.\left.\mathrm{N}_{2}\right)_{2}\left(\mathrm{P}^{\mathrm{Ph}} \mathrm{N}^{\mathrm{R}^{\prime}} \mathrm{P}^{\mathrm{Ph}}\right)_{2}\right]\left(\mathrm{R}^{\prime}=\mathrm{Bn}(\mathbf{1 6}) ; \mathrm{R}^{\prime}=\mathrm{Me}(\mathbf{1 7})\right.$ (Scheme 5). 
When $\mathrm{MoBr}_{3}(\mathrm{THF})_{3}$ was reduced using $\mathrm{Mg}$ in presence of 2 equiv of $\mathrm{P}^{\mathrm{Ph}} \mathrm{N}^{\mathrm{R}} \mathrm{P}^{\mathrm{Ph}}$ ligands, 16 and 17 were obtained; the $c$ is isomer was not observed. Unexpectedly, the desired Mo- $\mathrm{N}_{2}$ complexes could not be obtained from $\mathrm{Mg}$ reduction of commonly used Mo starting materials, such as, $\mathrm{MoCl}_{5}, \mathrm{MoCl}_{4}\left(\mathrm{Et}_{2} \mathrm{O}\right)$, and $\mathrm{MoCl}_{3}(\mathrm{THF})_{3}$.

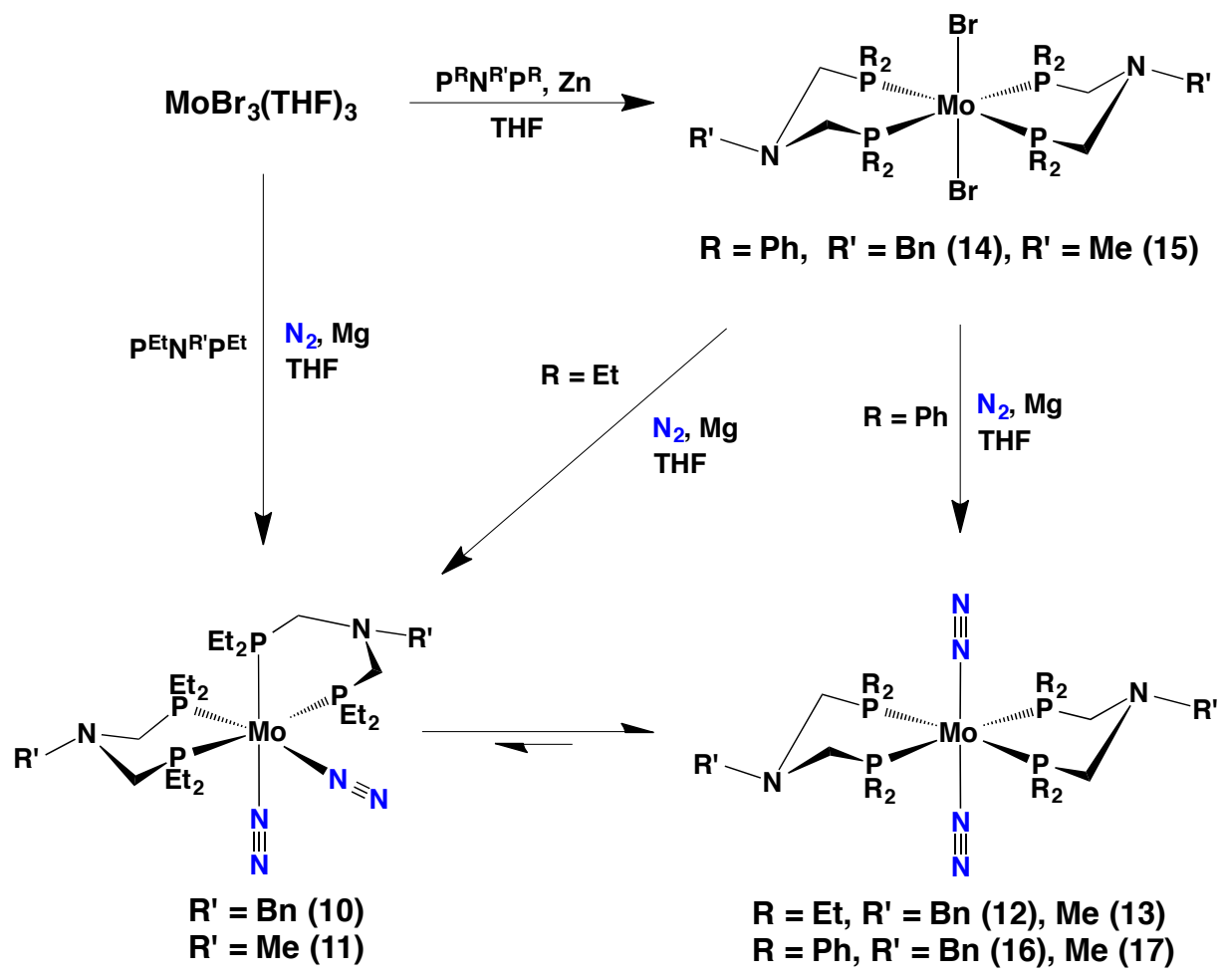

Scheme 5. Synthesis of Mo complexes containing PNP ligands [69].

The reactivity of 10, 12 and $\mathbf{1 7}$ was carried out with CO gas [69]. When a mixture of $\mathbf{1 0}$ and 12 was exposed to 1 atm $\mathrm{CO}$ gas, 10 converts to $c i s-\left[\mathrm{Mo}(\mathrm{CO})_{2}\left(\mathrm{P}^{\mathrm{Et}} \mathrm{N}^{\mathrm{Bn}} \mathrm{P}^{\mathrm{Et}}\right)_{2}\right]$ within 5 min, whereas 12 requires $40 \mathrm{~h}$ to convert to $>90 \%$ trans-[Mo(CO $\left.)_{2}\left(\mathrm{P}^{\mathrm{Et}} \mathrm{N}^{\mathrm{Bn}} \mathrm{P}^{\mathrm{Et}}\right)_{2}\right]$. Under identical reaction conditions when a THF solution of $\mathbf{1 7}$ was exposed to a $\mathrm{CO}$ environment the ${ }^{31} \mathrm{P}\left\{{ }^{1} \mathrm{H}\right\}$ NMR spectrum showed 17 and trans- $\left[\mathrm{Mo}(\mathrm{CO})_{2}\left(\mathrm{P}^{\mathrm{Ph}} \mathrm{N}^{\mathrm{Me}} \mathrm{P}^{\mathrm{Ph}}\right)_{2}\right]$ in a 1:1 mixture. After $24 \mathrm{~h}$, 
$\left[\mathrm{Mo}(\mathrm{CO})_{2}\left(\mathrm{P}^{\mathrm{Ph}} \mathrm{N}^{\mathrm{Me}} \mathrm{P}^{\mathrm{Ph}}\right)_{2}\right]$ was observed in 2:1 cis-trans ratio. However, loss of PNP ligand was also observed after this time.

Cyclic voltammetry experiments were performed on these Mo- $\mathrm{N}_{2}$ complexes and the results are summarized in Table 1 . As expected, the half-wave potentials of $\mathrm{Mo}^{\mathrm{I} / 0}$ couple are in accordance with the electron-donating ability of the substituents on the phosphorous atoms [70].

\section{Table 1}

Redox couples (V vs. $\mathrm{Cp}_{2} \mathrm{Fe}^{+/ 0}$ ) for Mo PNP complexes performed in THF 0.2 $\mathrm{M}\left[\mathrm{Bu}_{4} \mathrm{~N}\right]$ $\left[\mathrm{B}\left(\mathrm{C}_{6} \mathrm{~F}_{5}\right)_{4}\right]$ at $0.1 \mathrm{~V} \mathrm{~s}^{-1}[69]$.

\begin{tabular}{lll}
\hline Complexes & $\mathrm{Mo}^{\mathrm{I} / 0}\left(E_{1 / 2}\right)$ & $\begin{array}{l}\mathrm{Mo}^{\mathrm{II} / \mathrm{I}} \\
\left(E_{\mathrm{pa}}\right)\end{array}$ \\
\hline trans $-\left[\mathrm{Mo}\left(\mathrm{N}_{2}\right)_{2}\left(\mathrm{P}^{\mathrm{Et}} \mathrm{N}^{\left.\left.\mathrm{Bn} \mathrm{P}^{\mathrm{Et}}\right)_{2}\right](\mathbf{1 2})}\right.\right.$ & -1.06 & 0.02 \\
trans $-\left[\mathrm{Mo}\left(\mathrm{N}_{2}\right)_{2}\left(\mathrm{P}^{\mathrm{Et}} \mathrm{N}^{\mathrm{Me}} \mathrm{P}^{\mathrm{Et}}\right)_{2}\right](\mathbf{1 3})$ & -1.07 & 0.01 \\
trans $-\left[\mathrm{Mo}\left(\mathrm{N}_{2}\right)_{2}\left(\mathrm{P}^{\mathrm{Ph}} \mathrm{N}^{\left.\left.\mathrm{Bn} \mathrm{P}^{\mathrm{Ph}}\right)_{2}\right](\mathbf{1 6})}\right.\right.$ & -0.81 & 0.23 \\
trans $-\left[\mathrm{Mo}\left(\mathrm{N}_{2}\right)_{2}\left(\mathrm{P}^{\mathrm{Ph}} \mathrm{N}^{\mathrm{Me}} \mathrm{P}^{\mathrm{Ph}}\right)_{2}\right](\mathbf{1 7})$ & -0.82 & 0.18
\end{tabular}

Complexes 12 and 13, which contain with electron-donating ethyl groups, display more negative half-wave potentials (ca. $0.30 \mathrm{~V}$ ) when compared to 16 and $\mathbf{1 7}$, which contain electronwithdrawing phenyl substituents. All of these Mo complexes exhibit an irreversible wave for the $\mathrm{Mo}^{\mathrm{II} / \mathrm{I}}$ couple. Upon scanning through both the $\mathrm{Mo}^{\mathrm{I} / 0}$ and the $\mathrm{Mo}^{\mathrm{II} / \mathrm{I}}$ waves, loss of current was observed for the $\mathrm{Mo}^{\mathrm{I} / 0}$ couple in the returning cathodic scan resulting a quasi-reversible $\mathrm{Mo}^{\mathrm{I} / 0}$ wave. However, when the scan was stopped before reaching the $\mathrm{Mo}^{\mathrm{II} / \mathrm{I}}$ couple, the $\mathrm{Mo}^{\mathrm{I} / 0} \mathrm{wave}$ is reversible. This suggests that at higher oxidation states, one or both of the $\mathrm{N}_{2}$ ligands may dissociate from the metal center. 
In addition to the alkyl substituted $\mathrm{Mo}-\mathrm{N}_{2}$ complexes, a new series of trans$\left[\mathrm{Mo}\left(\mathrm{N}_{2}\right)_{2}\left(\mathrm{P}^{\mathrm{Et}} \mathrm{N}^{\mathrm{R}} \mathrm{P}^{\mathrm{Et}}\right)_{2}\right]$ complexes $(\mathrm{R}=\mathrm{Ph}(\mathbf{1 8})$, 2,6-difluorobenzyl (19); 3,5-difluorobenzyl (20); $\mathrm{CH}_{2} \mathrm{CH}_{2} \mathrm{NMe}_{2}$ (21); $\mathrm{CH}_{2}$-o-Py (22)) were prepared to examine their reactivity with acid [71]. These complexes were synthesized following a similar method as shown in Scheme 5. Although formation of cis-products were observed early in the reaction (ca. $2 \mathrm{~h}$ ), the reactions were stirred $>20 \mathrm{~h}$ in order to obtain exclusively the trans isomer. As expected, the identity of the pendant amine groups has a minimal effect on $\mathrm{N}_{2}$ ligand activation due to its distance from the metal center. Similar $v_{\mathrm{NN}}$ bands in the IR spectra and similar N-N bond distances in X-ray crystal structures further supported this trend.

Protonation studies were carried out with complexes 18-22 in order to understand the influence of pendant amines on the reactivity of these complexes [71]. Prior to this study, Tuczek and co-workers reported the reactivity trans-[Mo( $\left.\left.\mathrm{N}_{2}\right)_{2}(\mathrm{dppe})\left(\mathrm{pyNP}_{2}\right)\right][72],(\mathrm{dppe}=1,2-$ bis(diphenylphosphino)ethane, $\operatorname{pyNP}_{2}=N, N$-bis(diphenylphosphinomethyl)-2-amino-pyridine) with 3 equiv of $\mathrm{HBF}_{4} \cdot \mathrm{Et}_{2} \mathrm{O}$ and observed protonation at the dinitrogen ligand to form the Mo-hydrazido complex, as well as protonation of the pyridine nitrogen of the ligand [73]. In addition, literature reports on protonation reactions of Mo-bis(dinitrogen) complexes with traditional bidentate phosphine ligands [35] and metallocene containing disphophine ligands [74, 75], with strong acids (e.g. $\mathrm{HCl}, \mathrm{HOTf}, \mathrm{HBF}_{4} \cdot \mathrm{Et}_{2} \mathrm{O}$ etc.) afforded protonation at the dinitrogen ligand to generate hydrazido products [36, 76-79]. In our system, addition of 1 equiv of HOTf to a $10 \mathrm{mM}$ solution of $\mathbf{1 8}$ in THF- $d_{8}$ at $-40{ }^{\circ} \mathrm{C}$ generated ca. $25 \%$ of a 7 -coordinate 


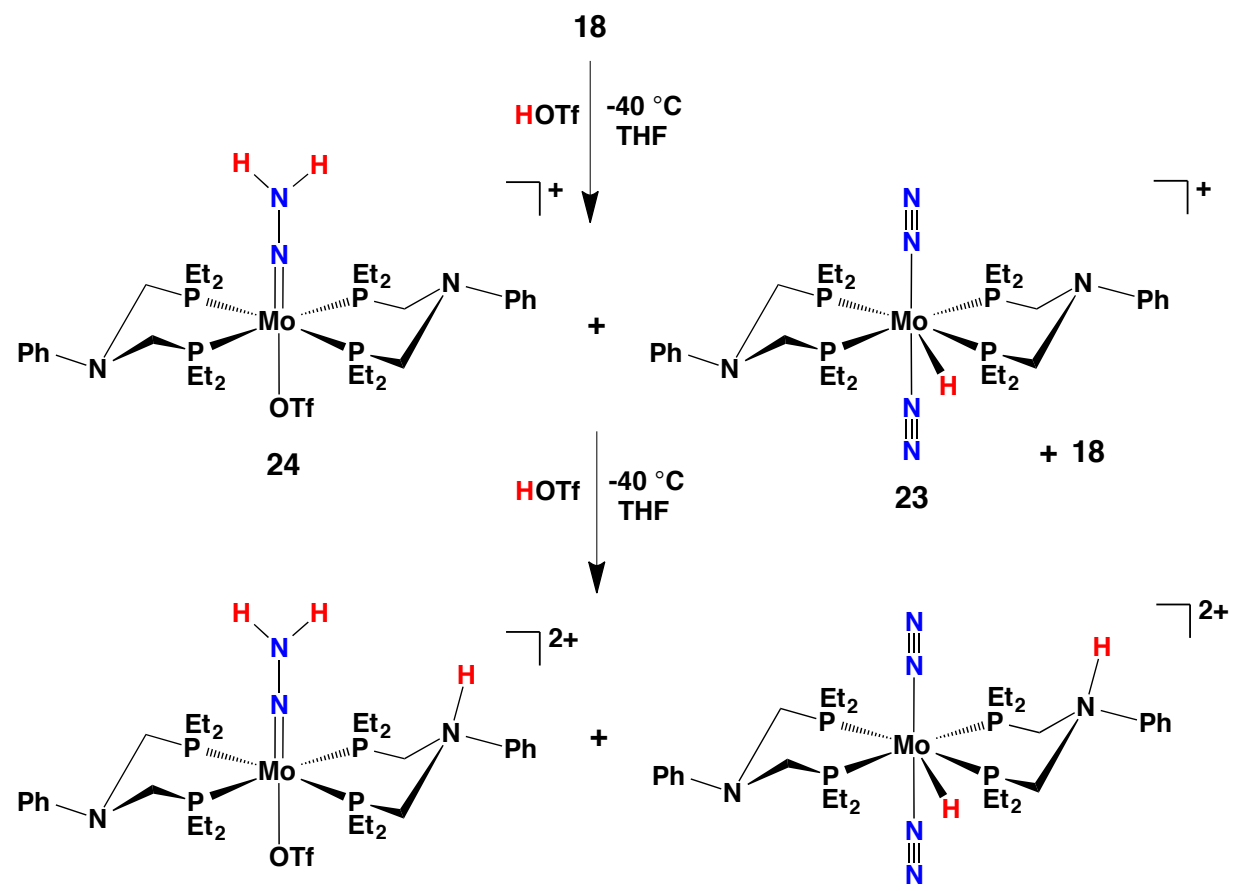

26

25

Scheme 6. Stepwise protonation of $\mathbf{1 8}$ with HOTf [71].

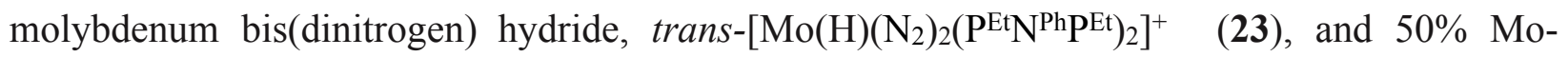
hydrazido triflate complex, trans-[Mo( $\left.\left(\mathrm{NNH}_{2}\right)(\mathrm{OTf})\left(\mathrm{P}^{\mathrm{Et}} \mathrm{N}^{\mathrm{Ph}} \mathrm{P}^{\mathrm{Et}}\right)_{2}\right]^{+}(\mathbf{2 4})$, and $25 \%$ of unreacted complex 18 (Scheme 6). Monitoring this reaction by in situ IR spectroscopy in THF at $-40{ }^{\circ} \mathrm{C}$ showed an immediate shift of the $v_{\mathrm{NN}}$ band from 1942 to $2022 \mathrm{~cm}^{-1}$, indicating the formation of a Mo-H complex. Addition of a second equiv of HOTf resulted in a further shift of the $v_{\mathrm{NN}}$ band to $2051 \mathrm{~cm}^{-1}$, which indicates protonation at the pendant amine site to generate $[\mathrm{Mo}(\mathrm{H})$ $\left.\left(\mathrm{N}_{2}\right)_{2}\left(\mathrm{P}^{\mathrm{Et}} \mathrm{N}^{\mathrm{Ph}}(\mathrm{H}) \mathrm{P}^{\mathrm{Et}}\right)\left(\mathrm{P}^{\mathrm{Et}} \mathrm{N}^{\mathrm{Ph}} \mathrm{P}^{\mathrm{Et}}\right)\right]^{2+}$ (25). Addition of more than 2 equiv of HOTf did not lead to further change in the position of the $v_{\mathrm{NN}}$ band, suggesting no further protonation at the pendant amine sites.

For protonation studies with HOTf, ${ }^{15} \mathrm{~N}_{2}$ labeled isotopologues of these complexes were prepared so that ${ }^{15} \mathrm{~N}$ NMR spectroscopy could be used to analyze the products [71]. In the ${ }^{15} \mathrm{~N}$ 
NMR spectrum of 18 at $-40{ }^{\circ} \mathrm{C}$, the proximal $\left(\mathrm{N}_{\mathrm{p}}\right)$ and distal $\left(\mathrm{N}_{\mathrm{d}}\right)$ nitrogen atoms appear at -40.8 and $-42.5 \mathrm{ppm}$, respectively. Upon addition of 1 equiv of HOTf, resonances for three products were observed in the ${ }^{15} \mathrm{~N}$ NMR spectrum. A new set of distal and proximal nitrogen resonances were formed at -37.2 and $-54.3 \mathrm{ppm}$, which were assigned to $23^{15 \mathrm{~N}}$, based on ${ }^{1} \mathrm{H}_{-}{ }^{15} \mathrm{~N}$ HMBC NMR data. The other product was assigned as $\mathbf{2 4}^{15 \mathrm{~N}}$ based on multiplicity, chemical shifts, and ${ }^{1} \mathrm{H}-{ }^{15} \mathrm{~N}$ HMBC data. Consistent with the in situ IR experiment, addition of a second equiv of HOTf protonates the pendant amine site to generate $25^{15 \mathrm{~N}}$ as evidenced by four ${ }^{15} \mathrm{~N}$ resonances resulting from two magnetically inequivalent ${ }^{15} \mathrm{~N}_{2}$ ligands. Warming the solution to $25^{\circ} \mathrm{C}$ results in loss of ${ }^{15} \mathrm{~N}$ signals for $\mathbf{2 5}^{15 \mathrm{~N}}$ and release of ${ }^{15} \mathrm{~N}_{2}$. However, the hydrazido product $\mathbf{2 4}{ }^{15 \mathrm{~N}}$ persisted in solution. Addition of more HOTf did not further protonate the nitrogen ligand site of $24^{15 N}$; instead, the pendant amine was protonated forming complex $26^{15 N}$. Even though electronwithdrawing phenyl substituent on nitrogen was present in complex 18, protonation at the pendant amine site was preferred over nitrogen ligand sites in $\mathbf{2 4}$.

With an understanding of the distribution of protonated products from HOTf addition to 18, we also investigated the reactivity of complexes 19 and $\mathbf{2 0}$, which contained more basic pendant amine substituents [71]. Similar to reactions with 18, the ${ }^{1} \mathrm{H}$ NMR and in situ IR data indicated the addition of 1 equiv of HOTf to complexes $\mathbf{1 9}$ and $\mathbf{2 0}$ formed a mixture of the Mohydrazido complexes, $\mathbf{2 7}$ and 28, and the 7-coordinate Mo-H products, 29 and 30, respectively. Notably, due to the higher basicity of the benzylamine groups, compared to the phenyl amines of 18, the addition of two additional equiv of HOTf resulted in protonation of both of the pendant amine sites, affording the tricationic Mo-H complexes 31 and 32, respectively (Scheme 7). Monitoring the in situ IR spectrum at $-40{ }^{\circ} \mathrm{C}$ readily identified the formation of the tricationic 
complexes 31 and 32, that display $v_{\mathrm{NN}}$ bands at 2069 and $2063 \mathrm{~cm}^{-1}$, respectively.

Complexes 21 and 22, which contain two protonation sites per pendant amine group, similarly afforded a Mo-H species upon addition of 1 equiv of HOTf [71]. Unfortunately, the protonated products that were formed upon the addition of two or more equiv of HOTf could not be readily characterized in THF due to poor solubility of these charged complexes.

Protonolysis of these $\operatorname{Mo}\left(\mathrm{N}_{2}\right)$ complexes to produce ammonia were also carried out with 100 equiv of HOTf. However, in case of $\mathbf{1 8}, \mathbf{1 9}$, and $\mathbf{2 1}$, only a trance amount of $\mathrm{NH}_{3}$ was detected and there was no evidence for $\mathrm{N}_{2} \mathrm{H}_{4}$ formation in these reactions.

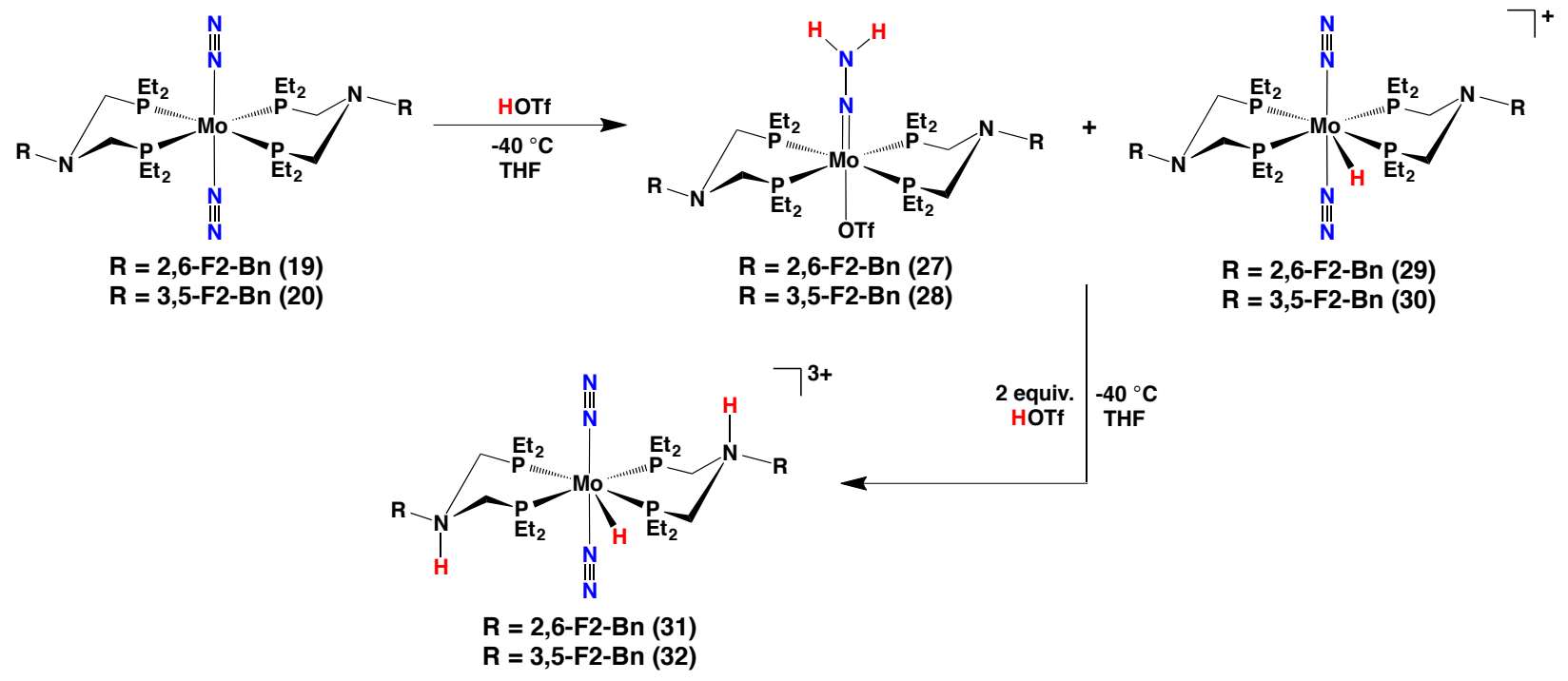

Scheme 7. Acid reactivity of complexes 19 and 20 showing the formation of a tricationic Mo-H species [71].

\subsection{Mo- $\mathrm{N}_{2}$ complexes with $\mathbf{P}^{\mathrm{E} t} \mathbf{P}^{\mathrm{NRR}}$ ligands}

Since the general acid reactivity patterns of the Mo- $\mathrm{N}_{2}$ complexes containing the PNP ligands resulted in Mo-H formation as the major product, a new series of bidentate phosphine ligands containing flexible pendant amine groups were designed so that the steric and electronic 
parameters of the pendant bases could be easily tuned to control the protonation site of the molecule, e.g. at the $\mathrm{N}_{2}$ ligand, pendant amine, or the metal center. In this new series of Mo- $\mathrm{N}_{2}$ complexes the pendant amines were not incorporated into the ligand backbone, rather the $\mathrm{P}^{\mathrm{E} t \mathrm{P}^{N R R^{\prime}}}$ ligand contained the pendant bases as terminal substituents on the phosphorus atom [80]. Synthesis of the desired Mo- $\mathrm{N}_{2}$ complexes was accomplished by ligand substitution reactions, treating the zero-valent complex trans-[Mo( $\left.\left(\mathrm{N}_{2}\right)_{2}\left(\mathrm{PMePh}_{2}\right)_{4}\right]$ with 1 equiv of the PEtPNR' ligand (Scheme 8).

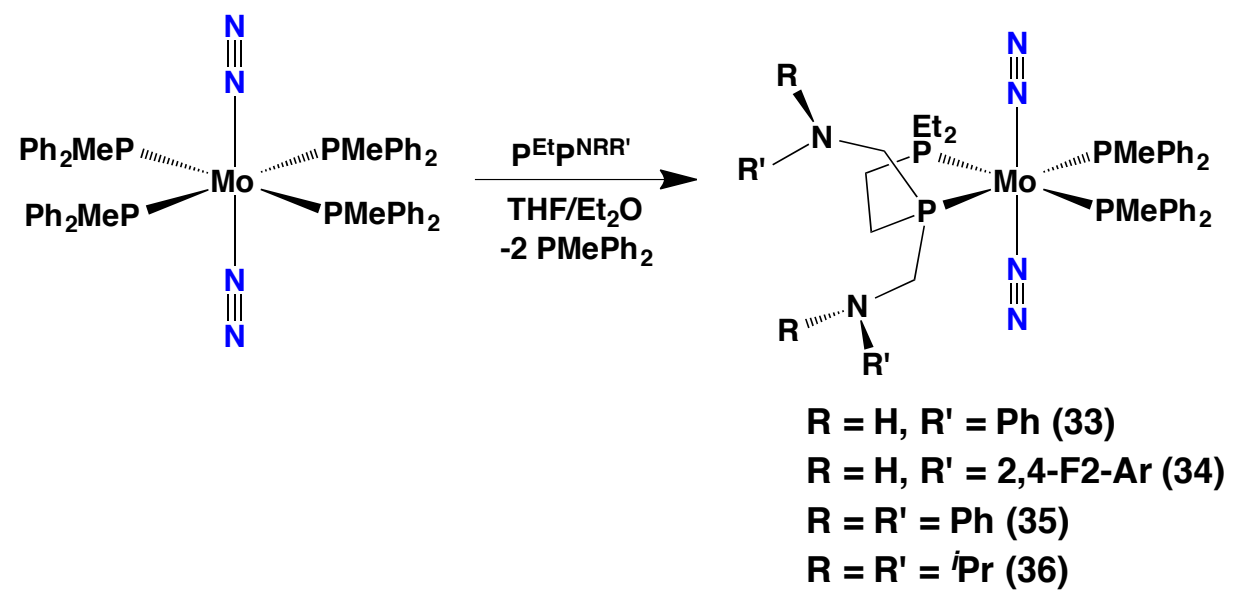

Scheme 8. Synthesis of Mo- $\mathrm{N}_{2}$ complexes with PEtPNRR' ligands [80].

The substituents on pendant amine were carefully chosen to span a range of $\mathrm{p} K_{\mathrm{a}}$ values and to more closely match the protonated amines $\mathrm{p} K_{\mathrm{a}}$ with the dinitrogen ligands. Since both are kinetically favored sites for protonation, $\mathrm{p} K_{\mathrm{a}}$ matching is crucial for protonation at the dinitrogen ligand rather than at the pendant amine site or the metal center. Apart from tuning the electronic nature of the ligands, it is also important to modulate the steric profile of the ligand to inhibit intermolecular proton transfer to the metal center. Complexes $\mathbf{3 5}$ and 36, which contain bulky phenyl and ${ }^{i} \operatorname{Pr}$ substituents on nitrogen (but have contrasting amine basicity), were synthesized 
to fulfill this criterion [80]. However, the most notable structural difference of the $\mathrm{P}^{\mathrm{E}} \mathrm{P}^{\mathrm{NRR}} \mathrm{N}^{\prime}$ motif from the previously described ligands is the flexibility of the pendant amines. Since the amine groups are not part of the chelate ring, they exhibit greater flexibility, which could potentially improve intramolecular proton delivery to the $\mathrm{N}_{2}$ ligand.

Protonation of these Mo complexes with HOTf were studied using multinuclear NMR and in situ IR spectroscopy. Treatment of $\mathbf{3 3}$ and $\mathbf{3 4}$ at $-40{ }^{\circ} \mathrm{C}$ in THF with 1 equiv of HOTf afforded a seven-coordinate Mo-H complex, as seen previously with $\mathrm{Mo}\left(\mathrm{N}_{2}\right)(\mathrm{PNP})_{2}$ complexes. Addition of a second equiv of HOTf resulted in protonation of the amine site (Scheme 9).
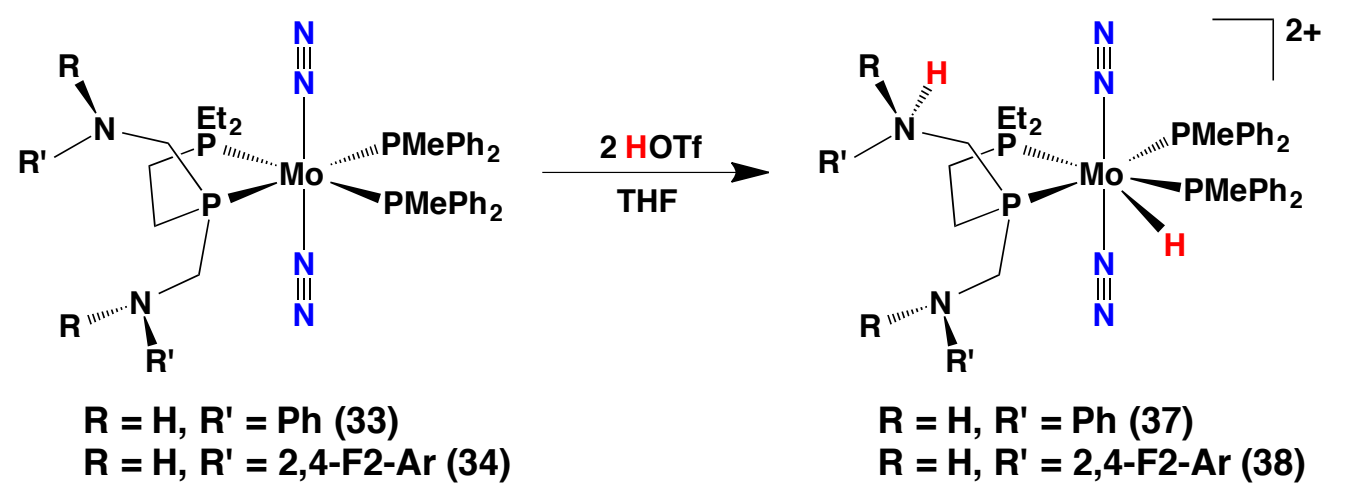

Scheme 9. Protonation reactions of $\mathbf{3 3}$ and $\mathbf{3 4}$ with 2 equiv HOTf [80].

Under similar reaction conditions, complex 35 does not form a Mo-hydride complex, and instead the Mo-hydrazido complex trans-[Mo(NNH 2$\left.)(\mathrm{OTf})\left(\mathrm{PMePh}_{2}\right)_{2}\left(\mathrm{P}^{\mathrm{Et}} \mathrm{P} \mathrm{N}(\mathrm{Ph}) 2\right)\right](\mathrm{OTf})(39)$ formed (ca. $50 \%$ ) when 1 equiv HOTf was added. A second equiv of HOTf was necessary for the reaction to go to completion (Fig. 5). Complex 39 was characterized by ${ }^{1} \mathrm{H},{ }^{31} \mathrm{P}$, and ${ }^{15} \mathrm{~N}$ NMR spectroscopy and by X-ray crystallography [80]. Notably, from the crystal structure of 39, an elongated N-N bond distance of $1.308(2) \AA$ is consistent with formation of the hydrazido ligand. In addition, the diphenylamine substituents are positioned exo with respect to the axial hydrazido ligand. This 
result is encouraging since protonation at the metal center was completely circumvented. The steric environment around the pendant amine might play an important role for such reactivity. Furthermore, phenyl groups might provide $\mathrm{p} K_{\mathrm{a}}$ matching to prevent protonation at the amine site.

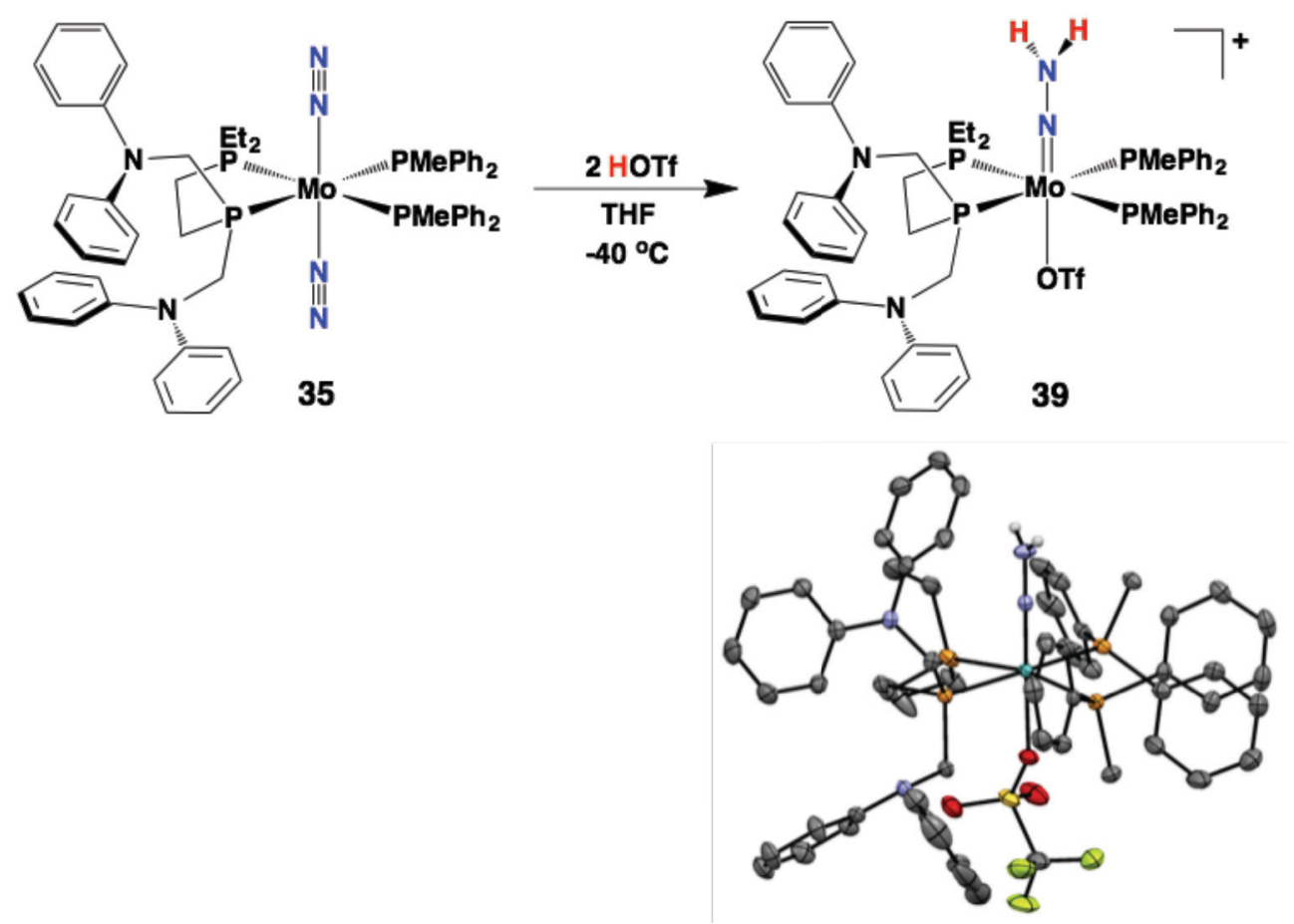

Fig. 5. Protonation of $\mathbf{3 5}$ to form the Mo-hydrazido complex 39. Thermal ellipsoids drawn at $30 \%$ probability. Hydrogen atoms are omitted for clarity, except for the protons of the hydrazido ligands are shown [80].

Accordingly, stepwise protonation experiments were performed with complex 36, which contains both sterically bulky and most basic pendant amine groups of this series. Addition of up to 2 equiv HOTf at $-40{ }^{\circ} \mathrm{C}$ forms monocationic complex $\mathbf{4 0}$ where one pendant amine site is protonated (Scheme 10) [80]. There was no evidence of protonation at the metal center. In all our previous cases, the metal hydride always formed prior to protonation at the amine site. This suggests that steric bulk and basicity of the amine group impedes the formation of the Mo-H product. Interestingly, addition of another 2 equiv of HOTf did not cause protonation to the other 
pendant amine site. This is also unprecedented in our previous systems, as highly basic amines were typically protonated at both amine sites in presence of excess acid. The close proximity of the amines in the same ligand is one plausible explanation for this unexpected result.

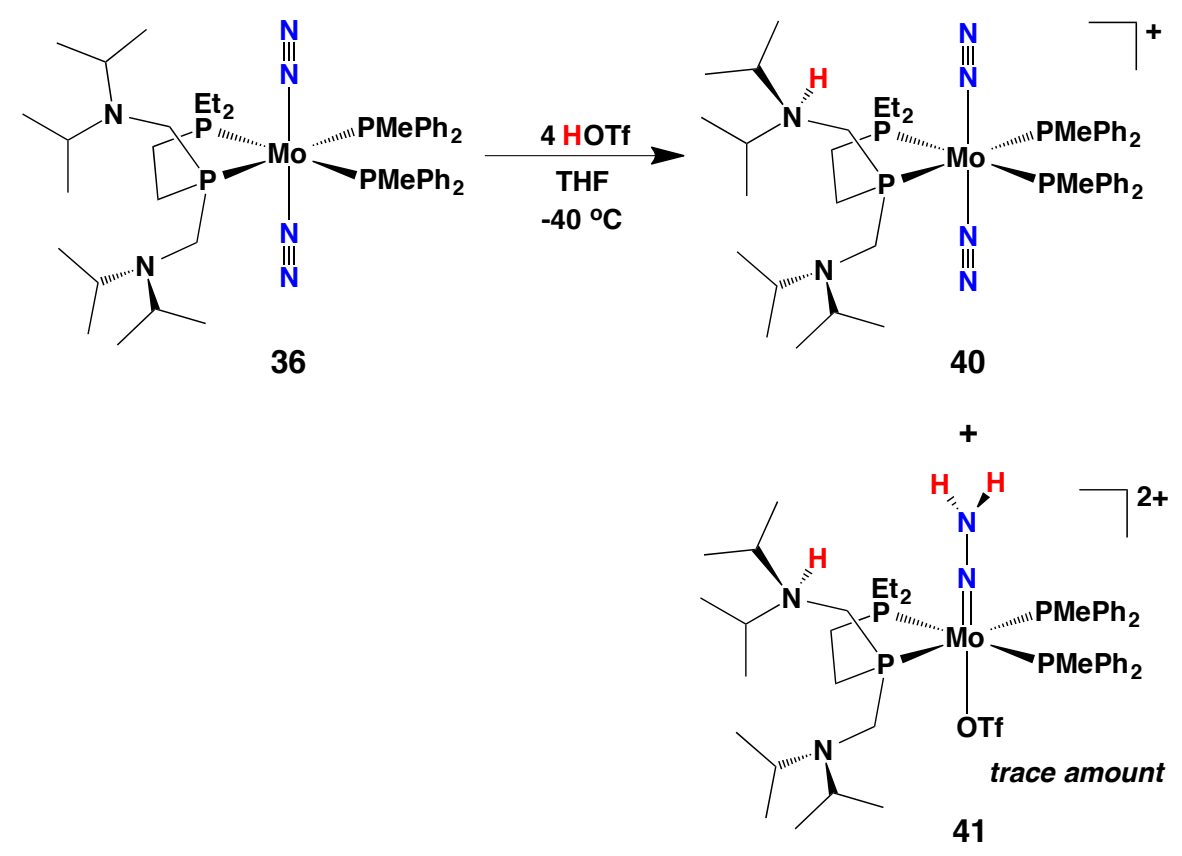

Scheme 10. Acid addition to $\mathbf{3 6}$ forms 40 containing a protonated pendant amine as the major product and a trace amount of $\mathbf{4 1}[80]$.

In addition to 40, two molybdenum hydrazido complexes, presumably isomers of trans$\left[\mathrm{Mo}\left(\mathrm{NNH}_{2}\right)(\mathrm{OTf})\left(\mathrm{PMePh}_{2}\right)_{2}\left(\mathrm{P}^{\mathrm{Etp}} \mathrm{P}^{\mathrm{N}(\mathrm{Pr}) 2}(\mathrm{H})\right)\right](\mathrm{OTf})_{2}(41)(\mathrm{Scheme} 10)$ were generated in small amounts, where with the protonated pendant amine is positioned near either the $\mathrm{NNH}_{2}$ or OTf ligand. Complex 40 loses $\mathrm{N}_{2}$ at room temperature; however 41 persists in solution at room temperature as observed by ${ }^{1} \mathrm{H}$ and ${ }^{31} \mathrm{P}$ NMR spectroscopy [80].

To compare the effect of pendant amines in the presence of exogeneous protons, structurally similar Mo dinitrogen complexes without the pendant amine $\mathbf{4 2}$ were also synthesized (Scheme 11). Treatment of $\mathbf{4 2}$ with 2 equiv of HOTf, cleanly forms trans- 
$\left[\mathrm{Mo}\left(\mathrm{NNH}_{2}\right)(\mathrm{OTf})\left(\mathrm{PMePh}_{2}\right)_{2}(\mathrm{depe})\right](\mathrm{OTf})(\mathbf{4 3})$. This finding was revealing because complex 33 and 34 both are structurally similar to $\mathbf{4 2}$, all providing very little steric protection around the metal center. However, acid addition to $\mathbf{3 3}$ and $\mathbf{3 4}$ formed Mo-H products with stoichiometric amounts of HOTf. It seems clear that the pendant amines likely play an important role in delivering a proton to the metal center.

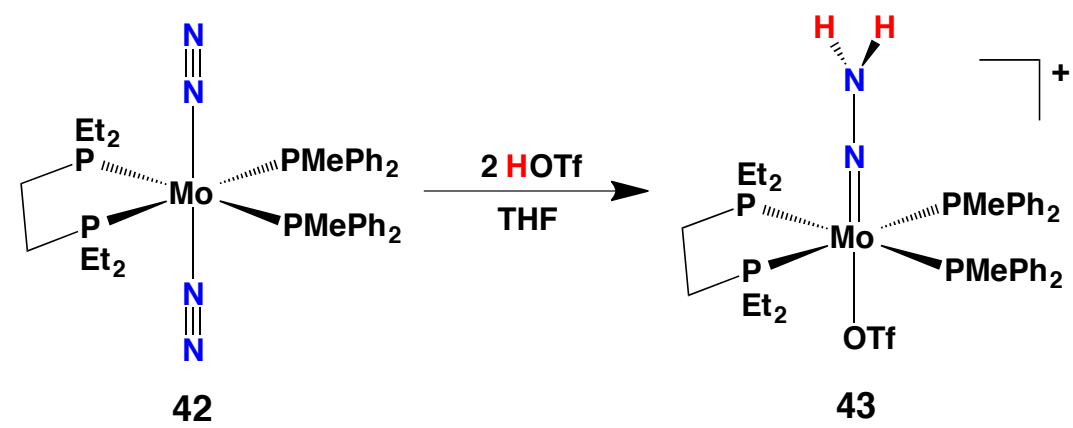

Scheme 11. Protonation of $\mathbf{4 2}$ to form the Mo-hydrazido complex 43 [80].

Reactions to produce ammonia from complex 33, 35, and $\mathbf{4 2}$ in presence of excess HOTf generated only 0.02-0.04 equiv of $\mathrm{NH}_{3}$ per Mo atom. Particularly, in case of $\mathbf{3 5}$ and $\mathbf{4 2}$, the stability of the intermediates $\mathbf{3 9}$ and $\mathbf{4 3}$ is a major obstacle, as these intermediates do not appear to react further with acid to produce $\mathrm{NH}_{3}[80]$.

\section{Tungsten $N_{2}$ complexes with $P^{R} N^{R^{\prime}} P^{R}$ ligands}

Continuing our efforts into the acid reactivity of group six metal complexes featuring chelating phosphine ligands with pendant amine groups in the secondary coordination sphere, a variety of low-valent W-dinitrogen complexes were prepared and compared with our previously described Mo systems [69]. Related to complexes 10-17, complexes containing one or two 
$\mathrm{P}^{\mathrm{R}} \mathrm{N}^{\mathrm{R}} \mathrm{P}^{\mathrm{R}}$ ligands, $\left(\mathrm{R}=\mathrm{Et}, \mathrm{R}^{\prime}=\mathrm{Me} ; \mathrm{R}=\mathrm{Ph}, \mathrm{R}^{\prime}=\mathrm{Me}\right)$ were synthesized using the known starting materials $\mathrm{WCl}_{4}\left(\mathrm{PPh}_{3}\right)_{2}$ and $\mathrm{WCl}_{4}(\mathrm{dppe})$ [68]. The complexes trans-[W( $\left.\left.\mathrm{N}_{2}\right)_{2}(\mathrm{dppe})\left(\mathrm{P}^{\mathrm{Et}} \mathrm{N}^{\mathrm{Me}} \mathrm{P}^{\mathrm{Et}}\right)\right]$ (44) and trans-[W( $\left.\left(\mathrm{N}_{2}\right)_{2}(\mathrm{dppe})\left(\mathrm{P}^{\mathrm{Ph}} \mathrm{N}^{\mathrm{Me}} \mathrm{P}^{\mathrm{Ph}}\right)\right](45)$, and the corresponding complexes without a pendant amine, trans-[W( $\left.\left.\mathrm{N}_{2}\right)_{2}(\mathrm{dppe})(\mathrm{dppp})\right](\mathbf{4 6}),(\mathrm{dppp}=1,3-\mathrm{bis}($ diphenylphosphino)propane $)$ and trans-[W( $\left.\left.\mathrm{N}_{2}\right)_{2}(\mathrm{dppe})(\mathrm{depp})\right]$ (47) (depp = 1,3-bis(diethylphosphino)propane) were synthesized following a similar procedure reported by Tuczek and co-workers (Scheme 12, top) [81]. Likewise, W-N $\mathrm{N}_{2}$ complexes containing two PNP ligands were synthesized by treating $\mathrm{WCl}_{4}\left(\mathrm{PPh}_{3}\right)_{2}$ with 2 equiv of PNP ligand in presence of excess Mg powder under a nitrogen atmosphere (Scheme 12, bottom). Depending on the substituents on phosphorous, either a cis or trans isomer was formed. For example, when the $\mathrm{P}^{\mathrm{Et}} \mathrm{N}^{\mathrm{Me}} \mathrm{P}$ Et ligand was used, cis$\left[\mathrm{W}\left(\mathrm{N}_{2}\right)_{2}\left(\mathrm{P}^{\mathrm{Et}} \mathrm{N}^{\mathrm{Me}} \mathrm{P}^{\mathrm{Et}}\right)_{2}\right]$ (48) was formed, whereas in case of $\mathrm{P}^{\mathrm{Ph}} \mathrm{N}^{\mathrm{Me}} \mathrm{P}$ Ph, trans$\left[\mathrm{W}\left(\mathrm{N}_{2}\right)_{2}\left(\mathrm{P}^{\mathrm{Ph}} \mathrm{N}^{\mathrm{Me}} \mathrm{P}^{\mathrm{Ph}}\right)_{2}\right](49)$, was obtained. 

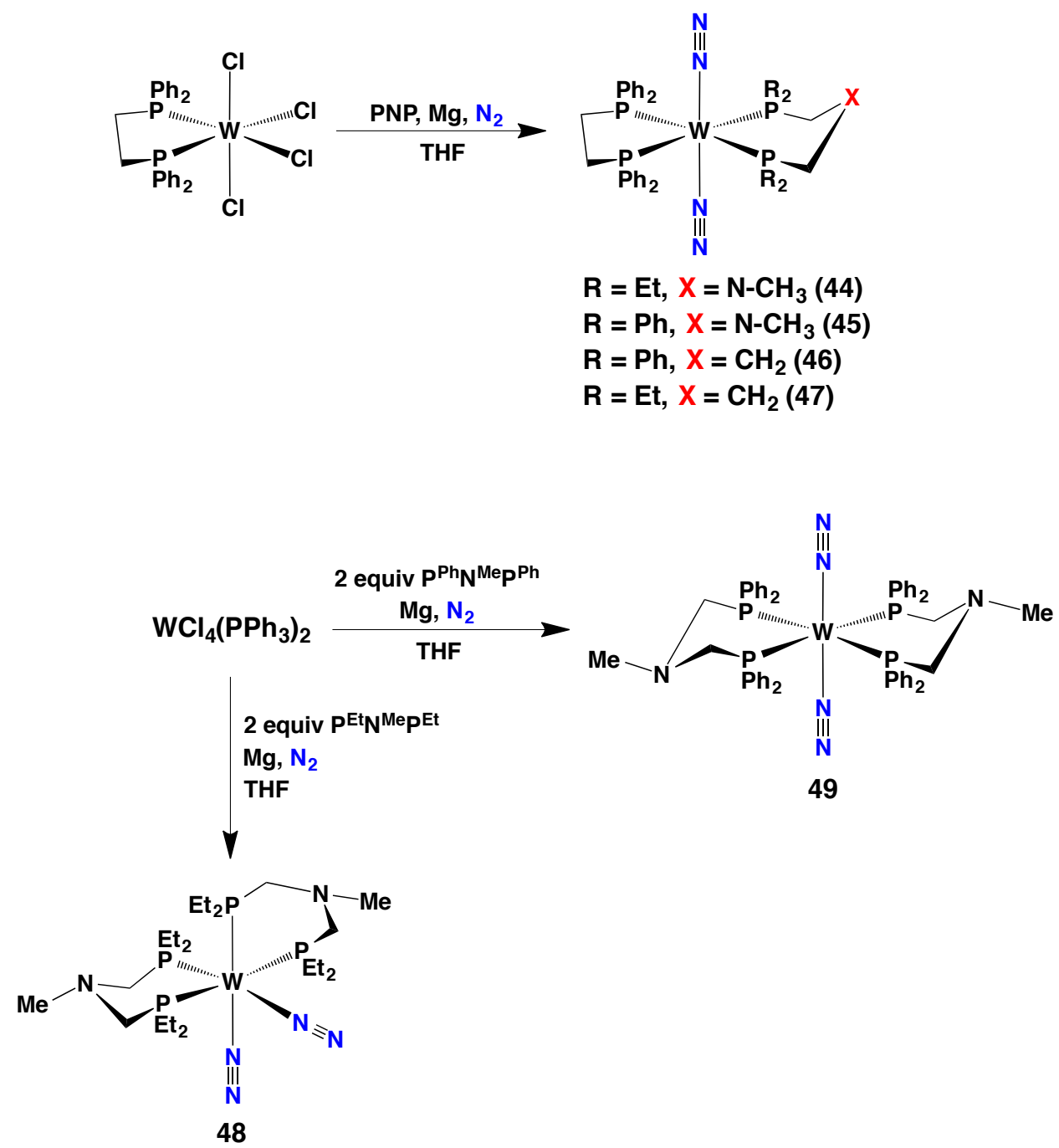

Scheme 12. Preparation of $\mathrm{W}-\mathrm{N}_{2}$ complexes with one PNP ligand (top) and two PNP ligands (bottom) [69, 82].

The electrochemistry of complexes $\mathbf{4 4}$ and $\mathbf{4 5}$ are similar to the Mo(PNP) complexes $\mathbf{1 2}, \mathbf{1 3}, \mathbf{1 6}$, and 17. In general, they exhibit a quasi-reversible $\mathrm{W}^{\mathrm{I} / 0}$ couple and an irreversible $\mathrm{W}^{\mathrm{I} / \mathrm{I}}$ couple. However, complex 46 shows a quasi-reversible $\mathrm{M}^{\mathrm{I} / \mathrm{I}}$ couple, which becomes reversible at higher scan rates. This may suggest that pendant amine could facilitate loss of $\mathrm{N}_{2}$ ligand by interacting with the metal center in the higher $\mathrm{W}$ oxidation states.

Initial studies examining stoichiometric protonation reactions focused on $\mathbf{4 4}$ with only 
one PNP ligand. For direct comparison, the structurally and electronically analogous complex 47 was also examined [82]. The products from the addition of 3 equiv of $\mathrm{HBF}_{4} \cdot \mathrm{Et}_{2} \mathrm{O}$ in $\mathrm{CD}_{2} \mathrm{Cl}_{2}$ were sensitive to temperature; when the solution temperature was kept rigorously low (-78 to -40 ${ }^{\circ} \mathrm{C}$ ), formation of $\mathrm{W}-\mathrm{H}$ complex $\mathbf{5 0}$ was identified by a characteristic hydride signal in the proton NMR spectrum, along with four inequivalent ${ }^{31} \mathrm{P}$ NMR signals. When this solution was warmed to $5{ }^{\circ} \mathrm{C}$ for a few minutes, the dicationic complex $\mathbf{5 1}$ with a protonated pendant amine was observed (Scheme 13). Warming this solution to room temperature liberated $\mathrm{N}_{2}$, and unidentified paramagnetic products were formed.

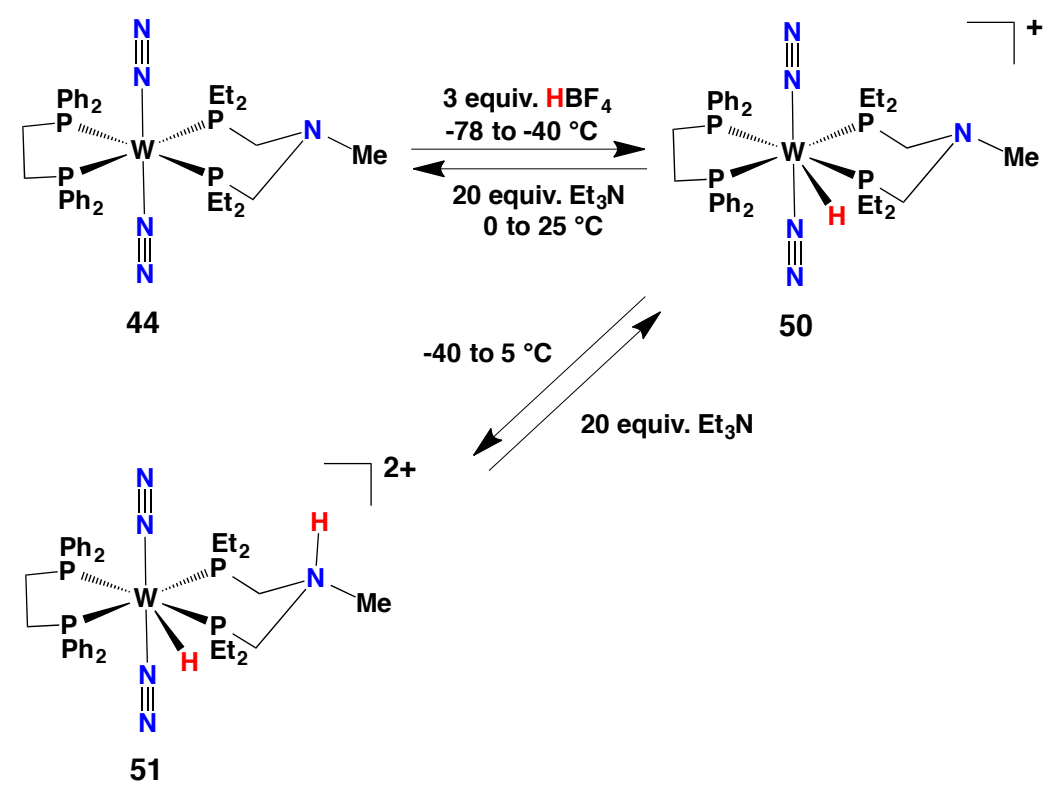

Scheme 13. Protonation and deprotonation behavior of 44 with 3 equiv of $\mathrm{HBF}_{4}$ in $\mathrm{CD}_{2} \mathrm{Cl}_{2}$ when the reaction temperature was kept at $-40{ }^{\circ} \mathrm{C}$ leading to formation of $\mathbf{5 0}$, then briefly warmed to 5 ${ }^{\circ} \mathrm{C}[82]$.

The protonation of the metal center as well as at the pendant amine can be reversed by addition of $\mathrm{Et}_{3} \mathrm{~N}$. For instance, treatment of $\mathbf{5 1}$ with 20 equiv of $\mathrm{Et}_{3} \mathrm{~N}$ at $-35{ }^{\circ} \mathrm{C}$ that rapidly deprotonated the pendant amine site and regenerated complex 50. When the solution was warmed to room 
temperature in presence of 20 equiv of $\mathrm{Et}_{3} \mathrm{~N}$, the metal center was also deprotonated to regenerate 44. However, 44 was not stable in presence of $\mathrm{HNEt}_{3}{ }^{+}$, but when in presence of 100 equiv $\mathrm{NEt}_{3}$, was found to persist in solution for $\sim 24 \mathrm{~h}$ at room temperature [82].

When the protonation of $\mathbf{4 4}$ was quickly warmed to room temperature for few minutes instead of being kept cold, a minor W-hydrazido product (52) (ca. 15\%) was also observed in addition to $\mathbf{5 1}$ (ca. 85\%, Scheme 14).

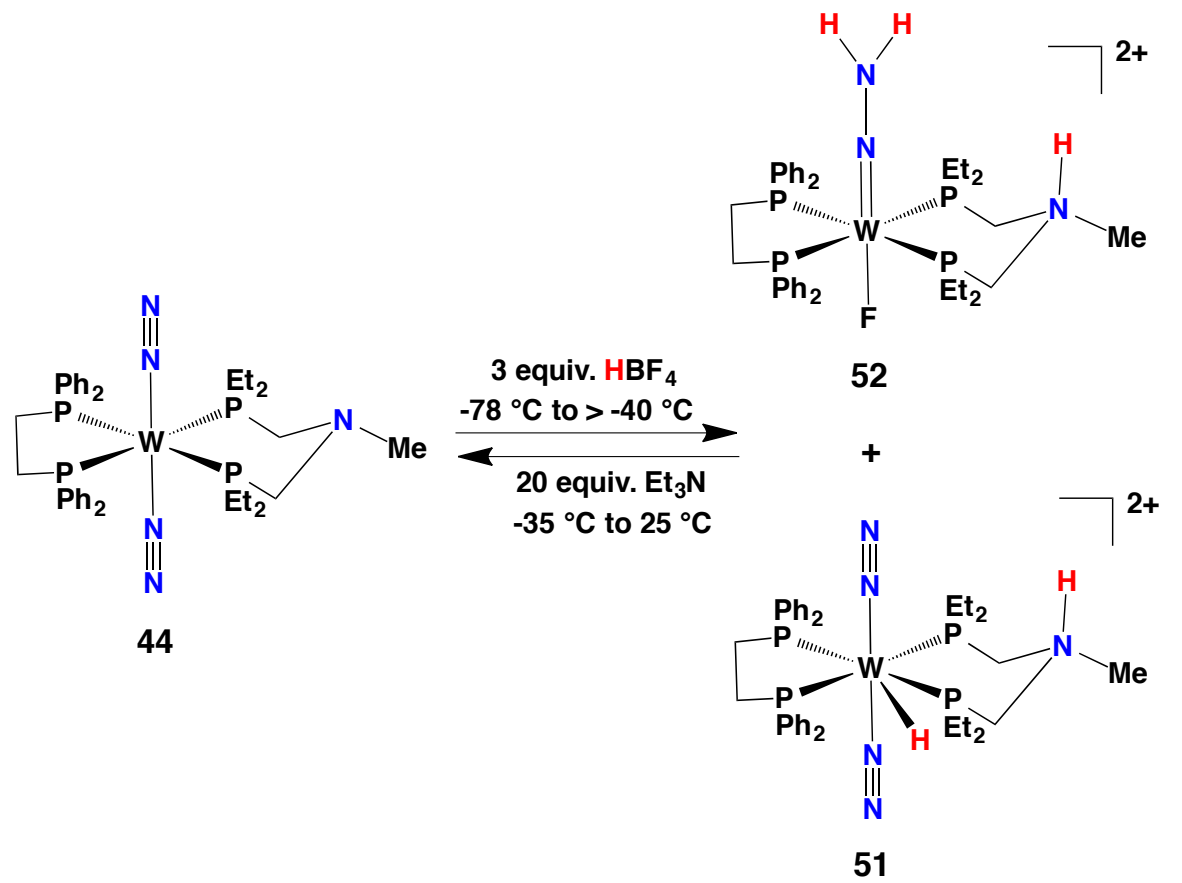

Scheme 14. Protonation of 44 with 3 equiv of $\mathrm{HBF}_{4}$ in $\mathrm{CD}_{2} \mathrm{Cl}_{2}$ when the reaction was warmed briefly at room temperature before returning to $-35^{\circ} \mathrm{C}$ for analysis [82].

In addition to protonation reactions with $\mathrm{HBF}_{4} \cdot \mathrm{Et}_{2} \mathrm{O}, \mathbf{4 4}$ was also treated with $\mathrm{HOTf}$ to determine if the counter anion effected the distribution of the products. The addition of 6 equiv of HOTf at $-78{ }^{\circ} \mathrm{C}$ and keeping the solution at $-40{ }^{\circ} \mathrm{C}$ during NMR experiments, $\sim 81 \%$ conversion to $\mathbf{5 1}$ and $18 \%$ conversion to $\mathbf{5 3}$ was observed (Scheme 15). Treatment of the product mixture of 51 and 53 with $\mathrm{NEt}_{3}$ at $-40{ }^{\circ} \mathrm{C}$ resulted in formation of 44 and $\mathbf{5 0}$, however $\mathrm{N}_{2}$ loss 
occurs at room temperature resulting in a paramagnetic product, based on the loss of ${ }^{31} \mathrm{P}$ NMR signals [82].

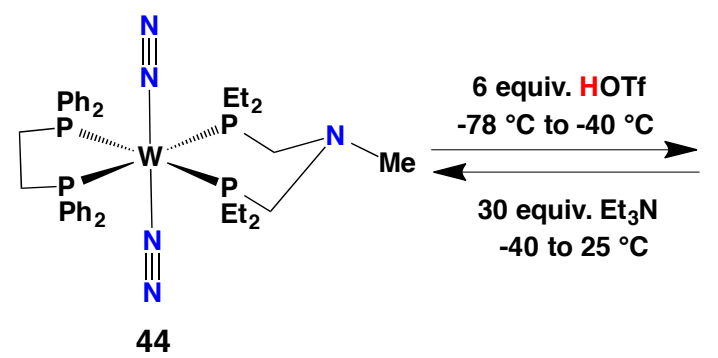

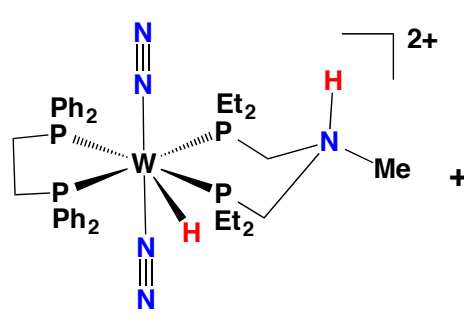

51

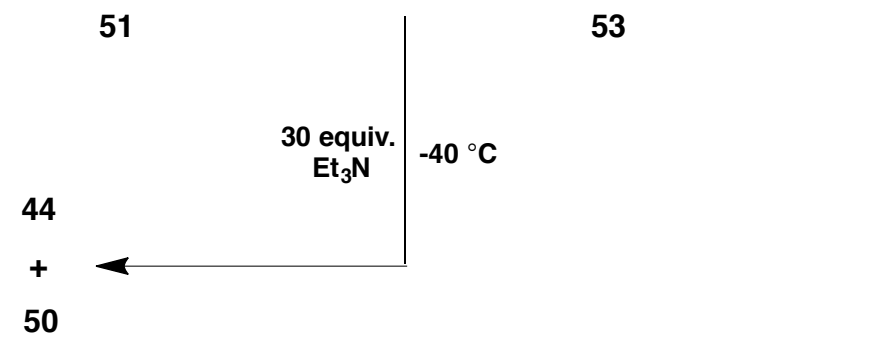

Scheme 15. Protonation of $\mathbf{4 4}$ with 6 equiv HOTf [82].

To compare the products formed in the protonation 44, the analogue without the pendant amine was examined under the same reaction conditions. Complex 47 was treated with 3 equiv of $\mathrm{HBF}_{4} \cdot \mathrm{Et}_{2} \mathrm{O}$, or HOTf at $-78{ }^{\circ} \mathrm{C}$ and then warmed to $-40{ }^{\circ} \mathrm{C}$ to collect NMR data, (Scheme 16). In the case of both acids, protonation occurred at the $\mathrm{N}_{2}$ ligand cleanly forming the hydrazido product $\left[\mathrm{W}\left(\mathrm{NNH}_{2}\right)(\mathrm{X})(\mathrm{dppe})(\mathrm{depp})\right]\left[\mathrm{X}^{\prime}\right],\left(\mathrm{X}=\mathrm{F}, \mathrm{X}^{\prime}=\mathrm{BF}_{4}(\mathbf{5 4}) ; \mathrm{X}=\mathrm{X}^{\prime}=\mathrm{OTf}(\mathbf{5 5})\right)$. Unlike 44, protonation at the metal center to generate the seven-coordinate W-H complex did not occur, suggesting that in $\mathbf{4 4}$ protonation of the pendant amine site may enable intra- or intermolecular proton transfer to the basic metal center [82]. 


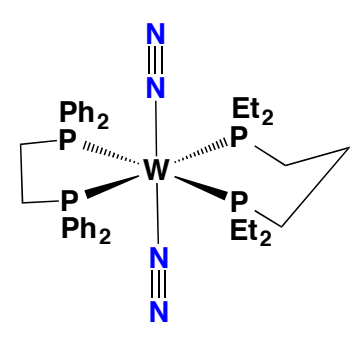

47

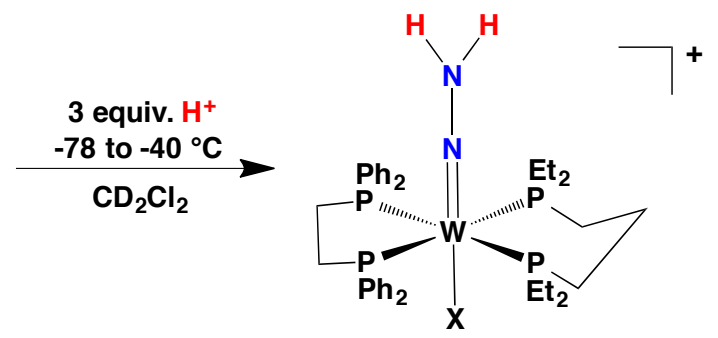

54 or 55

Scheme 16. Protonation of 47 with forming Mo-hydrazido complexes 54 and 55 . $\mathrm{H}^{+}=$ $\mathrm{HBF}_{4} \cdot \mathrm{Et}_{2} \mathrm{O}(\mathbf{5 4}, \mathrm{X}=\mathrm{F})$ or $\operatorname{HOTf}(\mathbf{5 5}, \mathrm{X}=\mathrm{OTf})[82]$.

With complexes 44 and 47 in hand, we examined whether the pendant amine-containing complex would lead to an enhancement of stoichiometric production of hydrazine or ammonia upon the addition of a large excess of acid. Treatment of complex 44 and 47 with 100 equiv of HOTf in $\mathrm{CH}_{2} \mathrm{Cl}_{2}$ at room temperature produced ammonia that was quantified by the indophenol method $[83,84]$. Complex 44 formed twice the amount of $\mathrm{NH}_{4}^{+}$per $\mathrm{W}$ center compared to 47 without pendant amine; i.e. 0.81 equiv of $\mathrm{NH}_{4}{ }^{+}$, and 0.40 equiv of $\mathrm{NH}_{4}{ }^{+}$, respectively, (Scheme 17) [82]. Reactions using isotopically labeled ${ }^{15} \mathrm{~N}_{2}$ gas confirmed that the $\mathrm{NH}_{4}^{+}$generated in these reactions was derived from the ${ }^{15} \mathrm{~N}_{2}$ ligands. This encouraging result illustrated that minor changes in the second-coordination sphere can have a dramatic effect in reactivity patterns of these $\mathrm{W}-\mathrm{N}_{2}$ complexes with protic reagents. Specifically, in the $\mathrm{N}_{2}$ reduction pathway, the pendant amine may play a role in promoting the formation of protonated $\mathrm{N}_{2}$ intermediates past the W-hydrazido species, which was a stable intermediate formed in the stoichiometric acid additions noted above. 


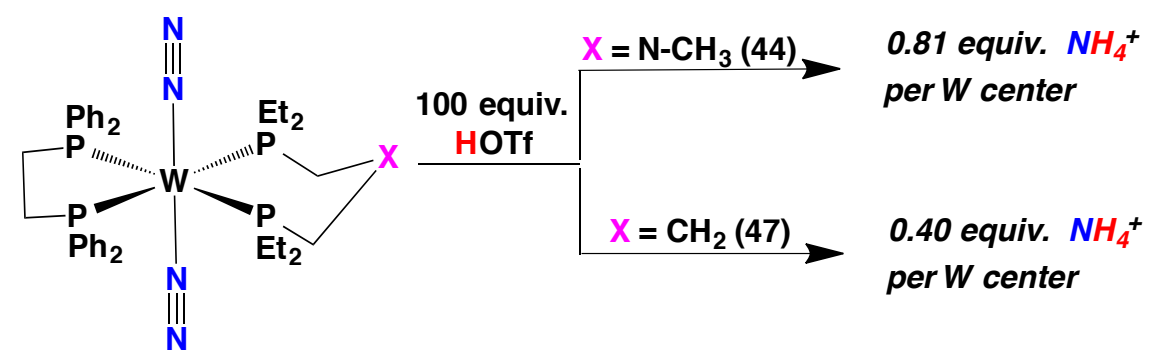

Scheme 17. Stoichiometric $\mathrm{NH}_{4}{ }^{+}$formation by 44 and 47 [82].

Analysis of the products from the reaction of $\mathbf{4 4}$ in Scheme 17, showed the hydrazido intermediate was absent; however, complex $\mathbf{5 5}$ persisted in the reaction mixture after HOTf addition to 47 . In the case of protonation of $\mathbf{4 4}$, the hydrazido intermediate, 53 would have a higher positive charge due to protonated pendant amine, which in turn could promote intermolecular electron transfer by shifting the reduction potential to a more positive value. Proton transfer to the $\mathrm{W}=\mathrm{NNH}_{2}$ species could follow this step or occur concomitantly with electron transfer. Although metal hydrides are generally believed to play an important role in reduction of dinitrogen to ammonia, it is unclear in this case whether preferential formation of W-H during the protonation reaction of $\mathbf{4 4}$ plays a role in producing greater amounts of $\mathrm{NH}_{4}^{+}$.

\section{Iron $N_{2}$ complexes with $P^{R} N^{R^{\prime}} P^{R}$ ligands}

In addition to the extensive studies we performed with Group 6 metals, renewed interest in welldefined iron-dinitrogen complexes [28-31, 34, 85] tailored for the reduction of $\mathrm{N}_{2}$ to $\mathrm{NH}_{3}[24-26$, 86-89] motivated us to investigate the synthesis and reactivity of iron-diphosphine complexes containing pendant amines. Recently, we synthesized octahedral iron(II) dinitrogen complexes with the general formula trans-[Fe(X)( $\left.\left.\mathrm{N}_{2}\right)\left(\mathrm{P}^{\mathrm{E}} \mathrm{N}^{\mathrm{Me}} \mathrm{P}^{\mathrm{Et}}\right)(\mathrm{dmpm})\right]^{+}(\mathrm{X}=\mathrm{H}, \mathrm{Cl}, \mathrm{Br}$; dmpm $=1,1-$ 
dimethylphosphinomethane) [90]. In particular, trans-[Fe(H)( $\left.\left.\mathrm{N}_{2}\right)\left(\mathrm{P}^{\mathrm{Et}} \mathrm{N}^{\mathrm{Me}} \mathrm{P}^{\mathrm{Et}}\right)(\mathrm{dmpm})\right]\left[\mathrm{BPh}_{4}\right](\mathbf{5 6})$ was reacted under a variety of conditions relevant to $\mathrm{N}_{2}$ reduction (Scheme 18). In the presence of 1 equiv of strong acid ( $\mathrm{HOTf}$ or $\left.\left[\mathrm{H}\left(\mathrm{OEt}_{2}\right)_{2}\right]\left[\mathrm{B}\left(\mathrm{C}_{6} \mathrm{~F}_{5}\right)_{4}\right]\right)$ at $-40{ }^{\circ} \mathrm{C}, \mathbf{5 6}$ is protonated at the pendant amine nitrogen to generate a mixture of endo/exo isomers 57, which were characterized in solution by IR and NMR spectroscopy. The ${ }^{31} \mathrm{P}$ NMR spectrum and ${ }^{15} \mathrm{~N}$ NMR spectrum of isotopically enriched ${ }^{15} \mathrm{~N}_{2}-\mathbf{5 7}$ both revealed that the ratio of endo/exo isomers in solution is approximately 3:1. Protonation of the ligand on going from 56 to 57 increases the $\mathrm{N}_{2}$ stretching frequency by $25 \mathrm{~cm}^{-1}$, going from $2114 \mathrm{~cm}^{-1}$ to $2139 \mathrm{~cm}^{-1}$, respectively. Furthermore, 57 can be cleanly deprotonated with $\mathrm{NEt}_{3}$ to regenerate $\mathbf{5 6}$, whose reaction can be monitored by in situ IR spectroscopy. Complex 56 reversibly binds $\mathrm{H}_{2}$ to generate 58 [91] and also binds $\mathrm{NH}_{3}$ with the concomitant release of $\mathrm{N}_{2}$ to form 59, in which the latter was characterized by NMR spectroscopy and X-ray crystallography [90]. Treatment of 56 with excess acid (50 equiv $\left.\mathrm{H}_{2} \mathrm{SO}_{4}\right)$ did not generate a detectable amount of ammonia.

Electrochemical analysis on $56\left(-24^{\circ} \mathrm{C}, \mathrm{CH}_{2} \mathrm{Cl}_{2}\right)$ reveals an irreversible $\mathrm{Fe}^{\mathrm{II} / \mathrm{I}}$ reduction wave at $-2.58 \mathrm{~V}\left(\mathrm{vs} . \mathrm{Fc}^{0 /+}\right)$. Low temperature electrochemical analysis of $\mathbf{5 7}$ results in a shift of the onset of the irreversible $\mathrm{Fe}^{\mathrm{II} / \mathrm{I}}$ reduction wave by $+0.33 \mathrm{~V}$, which is expected due to the increase in overall charge [90]. 

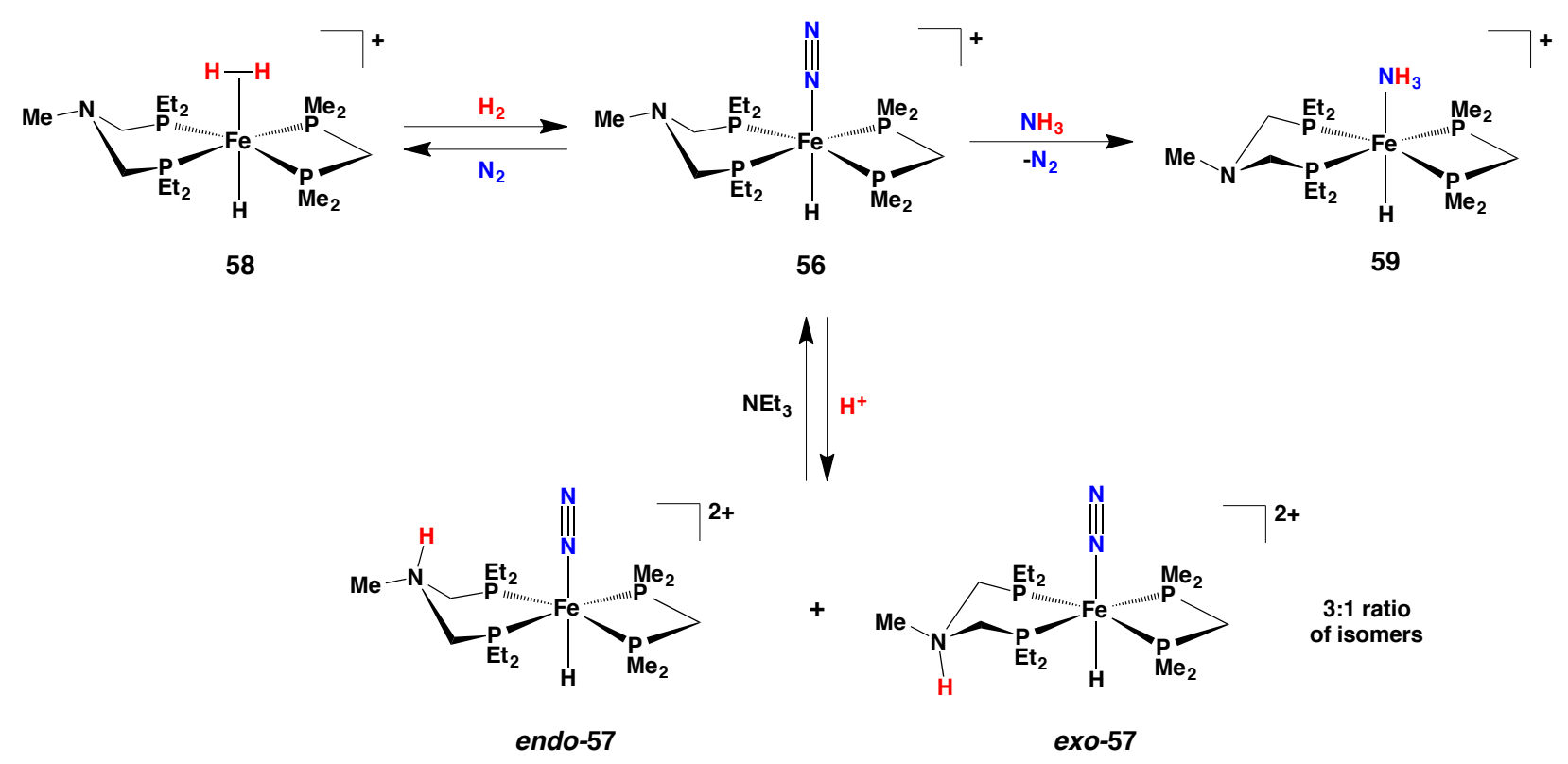

Scheme 18. Reactions of 56 with acid, hydrogen, and ammonia [90].

Computational analysis on the reactivity of $\mathbf{5 6}$ provided some insight into the energetics of $\mathrm{N}_{2}$ binding and protonation. The binding affinity of $\mathrm{N}_{2}$ to $\mathbf{5 6}$ is favorable by $10.1 \mathrm{kcal} / \mathrm{mol}$, while by comparison the CO binding affinity for the isoelectronic complex trans- $\left[\mathrm{Fe}(\mathrm{H})(\mathrm{CO})\left(\mathrm{P}^{\mathrm{E}} \mathrm{N}^{\mathrm{Me}} \mathrm{P}^{\mathrm{Et}}\right)\right.$ $(\mathrm{dmpm})]^{+}$is much stronger $(36.0 \mathrm{kcal} / \mathrm{mol})$. Protonation to form endo-57 was found to be 43.5 $\mathrm{kcal} / \mathrm{mol}$ more favorable than protonation at the distal nitrogen atom of coordinated $\mathrm{N}_{2}$, indicating that the dinitrogen ligand is $31.9 \mathrm{p} K_{\mathrm{a}}$ units more acidic [90]. This agrees with the experimental observations of $\mathbf{5 7}$ and suggests that a less basic pendant amine, in combination with a more activated $\mathrm{N}_{2}$ ligand, should bias the $\mathrm{N}_{2}$ ligand more towards protonation upon the addition of acid.

In order to access more electron-rich iron dinitrogen complexes, attempts were made to synthesize the five-coordinate $\mathrm{Fe}(0)$ complex $\mathrm{Fe}\left(\mathrm{N}_{2}\right)\left(\mathrm{P}^{\mathrm{E}} \mathrm{N}^{\mathrm{Me}} \mathrm{P}^{\mathrm{Et}}\right)(\mathrm{dmpm})$ from complex 56 [90]. However, each approach led to dmpm ligand loss and the formation of the crystallographically 
characterized iron hydride complex $\mathrm{HFe}\left(\mathrm{Et}_{2} \mathrm{PC}(\mathrm{H}) \mathrm{N}(\mathrm{Me}) \mathrm{CH}_{2} \mathrm{PEt}_{2}\right)\left(\mathrm{P}^{\mathrm{Et}} \mathrm{N}^{\mathrm{Me}} \mathrm{P}^{\mathrm{Et}}\right)$ (60) which contains a three-membered Fe-C-P metallacycle and a second $\mathrm{P}^{\mathrm{Et}} \mathrm{N}^{\mathrm{Me}} \mathrm{P}^{\mathrm{Et}}$ ligand (Fig. 6) [90]. The most direct and convenient method for synthesizing $\mathbf{6 0}$ was by mixing $\mathrm{FeCl}_{2}$ and two
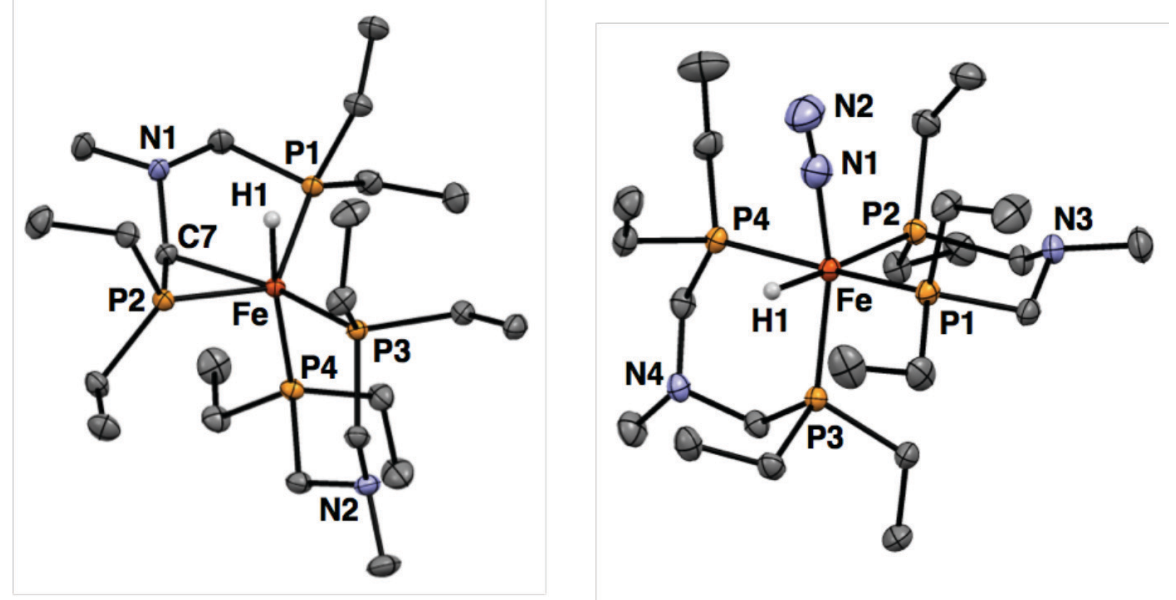

Fig. 6. Molecular structures of 60 (left) and the cation 61 (right). Thermal ellipsoids drawn at $30 \%$ probability. Hydrogen atoms are omitted for clarity except for the hydrogen atoms bound to Fe $[90,92]$.

equivalents of free ligand $\mathrm{P}^{\mathrm{Et}} \mathrm{N}^{\mathrm{Me}} \mathrm{P} E \mathrm{Et}$ in the presence of excess magnesium powder, leading to isolated yields of $39 \%$ after crystallization. In this case, it is possible that the target $\mathrm{Fe}(0)$ complex is formed as a transient intermediate that then undergoes ligand $\mathrm{C}-\mathrm{H}$ activation.

Detailed experimental and computational investigations involving proton/electron additions to $\mathbf{6 0}$ were conducted [92]. The overall reaction (Scheme 19) involves the addition of 


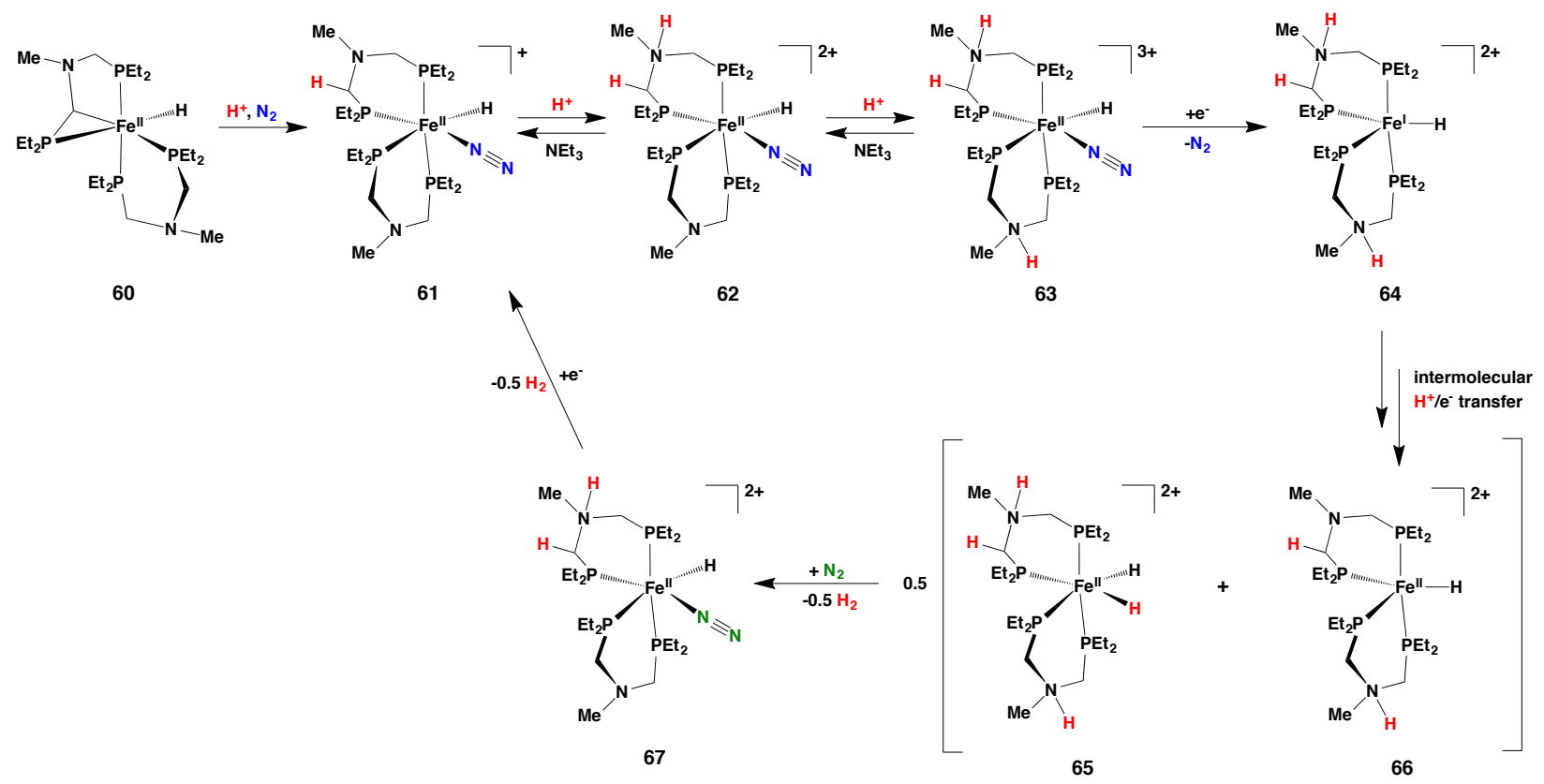

Scheme 19. Investigation of proton and electron additions to complex 60 [92].

three protons followed by two electrons, resulting in expulsion of $\mathrm{H}_{2}$ and uptake of $\mathrm{N}_{2}$ in the final steps, relevant to the proposed "E4" state in active site of iron-molybdenum cofactor of nitrogenase after the uptake of four protons and electrons $[11,12,93]$. Beginning with complex 60, the reactions can be conveniently followed by in situ IR analysis of the $\mathrm{N}_{2}$ stretching band (Fig. 7). After the addition of 1 equiv acid $\left(\left[\mathrm{H}\left(\mathrm{OEt}_{2}\right)_{2}\right]\left[\mathrm{B}\left(\mathrm{C}_{6} \mathrm{~F}_{5}\right)_{4}\right]\right)$, the metallacyclic carbon atom in 60 is protonated with concomitant uptake of $\mathrm{N}_{2}$, generating the cationic cis- $\left[\mathrm{Fe}(\mathrm{H})\left(\mathrm{N}_{2}\right)\right.$ $\left.\left(\mathrm{P}^{\mathrm{Et}} \mathrm{N}^{\mathrm{Me}} \mathrm{P}^{\mathrm{Et}}\right)_{2}\right]^{+}$complex $61\left(v_{\mathrm{NN}}=2122 \mathrm{~cm}^{-1}\right)$, which was structurally characterized [92]. Next, 61 can be protonated further with two sequential additions of 1 equiv of acid, generating complex 62 and 63, and shifting the observed $v_{\mathrm{NN}}$ band by +16 and $+23 \mathrm{~cm}^{-1}$ after each protonation, respectively. As in the case of complexes 56 and 57, deprotonation with base 
regenerates 61. Addition of a one electron reductant $\left(\mathrm{Cp}_{2} \mathrm{Co}\right)$ to 63 yields the proposed $\mathrm{Fe}(\mathrm{I})$ complex 64, which was characterized by X-band EPR spectroscopy. This reduction also results in a cascade of reactions, supported by DFT calculations, involving intermolecular proton and electron rearrangements, ultimately yielding the proposed Fe(II) intermediates 65 and $\mathbf{6 6}$. The formation of $\mathbf{6 5}$ was also supported by its independent synthesis from 60 with hydrogen gas, followed by the addition of 2 equiv of acid. Finally, the uptake of $\mathrm{N}_{2}$ by $\mathbf{6 6}$ and/or the liberation of $\mathrm{H}_{2}$ from 65 with subsequent $\mathrm{N}_{2}$ uptake generated complex 67. Computational analysis slightly favors the latter scenario, which is lower in energy by $2.4 \mathrm{kcal} / \mathrm{mol}$ [92].

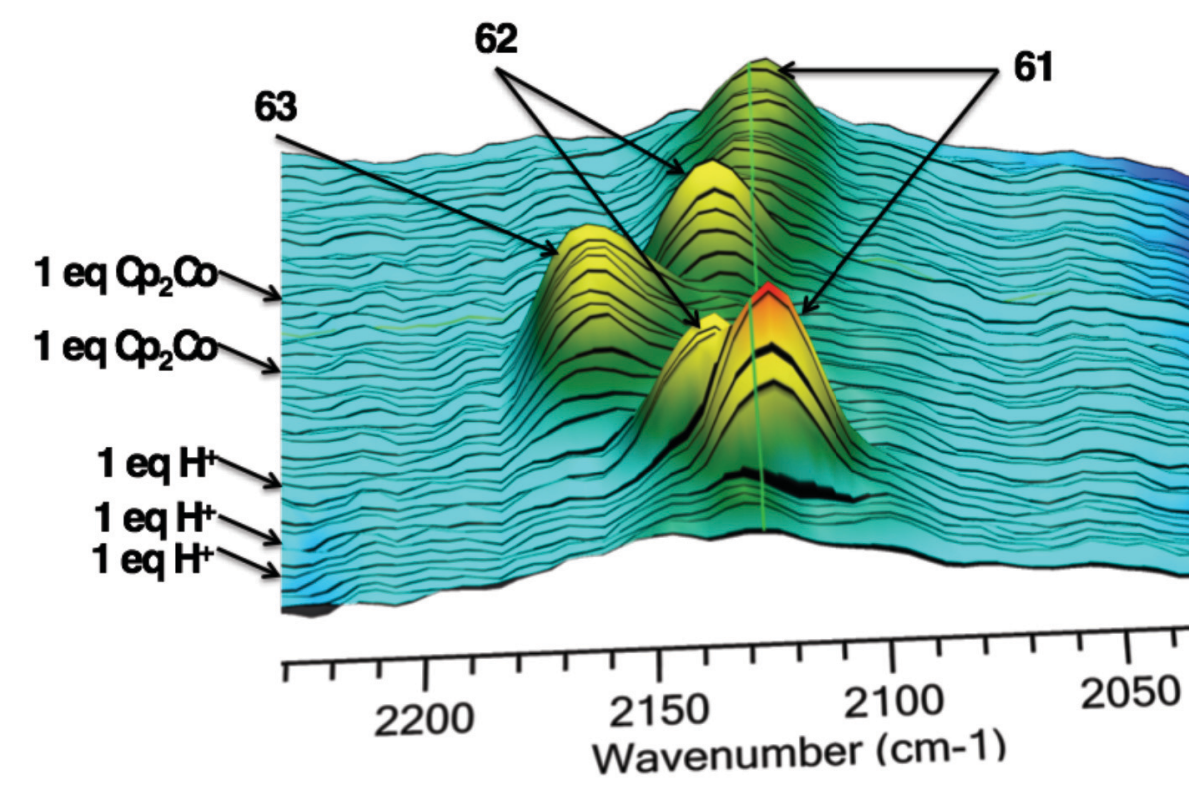

Fig. 7. In Situ IR spectra recorded at $-78{ }^{\circ} \mathrm{C}$ in THF of the sequential addition of protons and electrons to 61. Figure was adapted from ref. [89], with permission of the copyright holders. (Z.M. Heiden, S. Chen, L.A. Labios, R.M. Bullock, E.D. Walter, E.L. Tyson, M.T. Mock, Organometallics 33 (2014) 1333-1336.). Copyright 2014 American Chemical Society [92].

\section{Vanadium halide complexes with $P^{R} N^{R^{\prime}} P^{R}$ and $P^{R}{ }_{2} N^{R_{2}^{\prime}}$ ligands}


In addition to the group 6 complexes described above, recent efforts investigated the coordination chemistry of organometallic vanadium complexes containing $\mathrm{P}^{\mathrm{R}} \mathrm{N}^{\prime} \mathrm{P}^{\mathrm{R}}$, and $\mathrm{P}^{\mathrm{R}}{ }_{2} \mathrm{~N}^{\mathrm{R}_{2}}$ ligands. Vanadium complexes bearing traditional phosphine ligands have been shown to coordinate $\mathrm{N}_{2}$ [94] and in some cases produce ammonia and hydrazine upon treatment with acid [95-97]. These results motivated our studies to explore vanadium complexes containing pendant amines. We recently synthesized a series of vanadium halide complexes containing diphosphines and pendant amines, according to Scheme 20 [98].

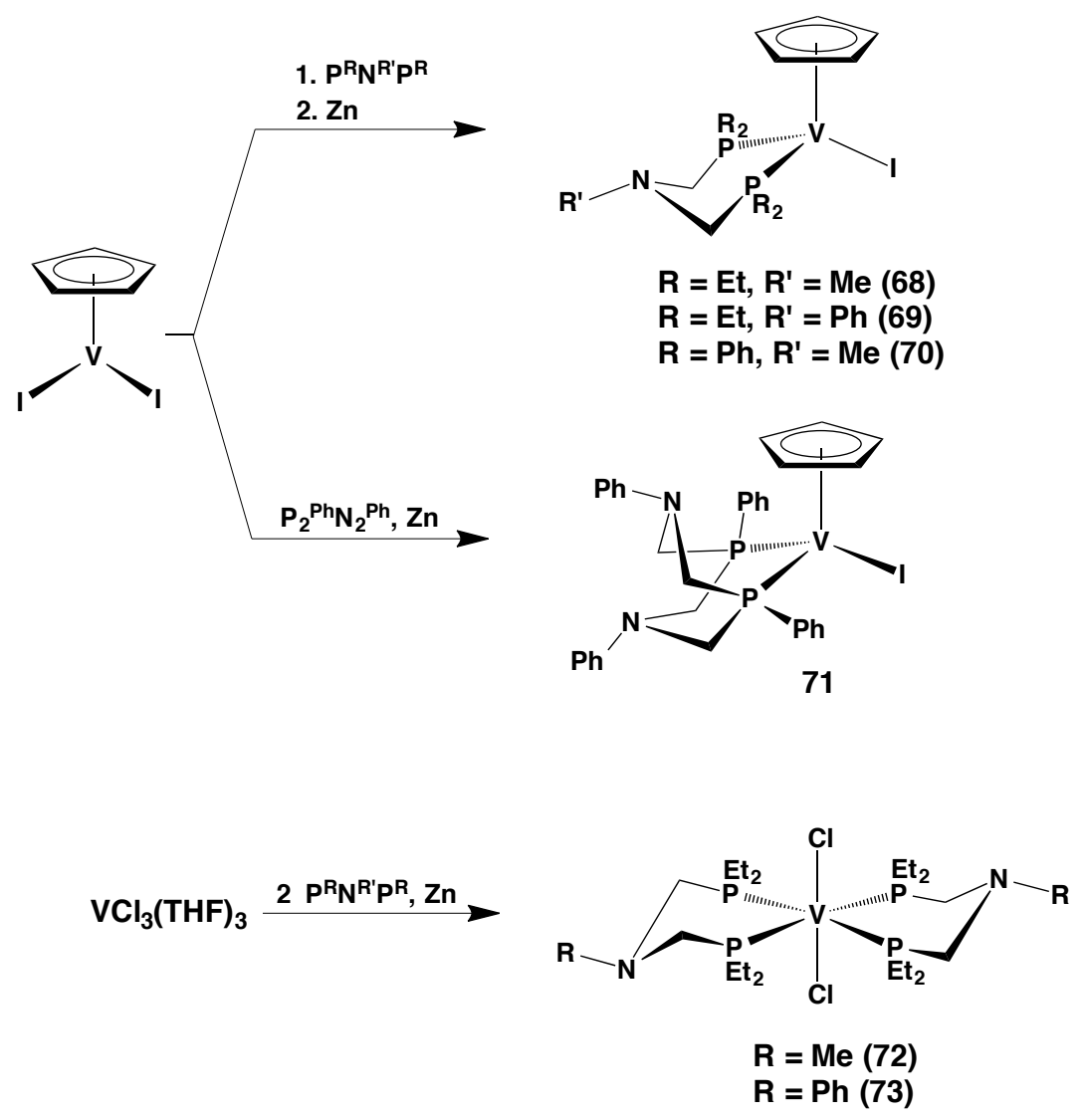

Scheme 20. Synthesis of vanadium complexes containing pendant amines [98].

Using the precursor $\mathrm{Cp}_{2} \mathrm{VI}_{2}$, which is crucial to prevent undesirable disproportionation reactions [99], piano-stool complexes 68-70 was synthesized in two steps by first isolating the diiodide complexes $\mathrm{CpVI}_{2}\left(\mathrm{P}^{\mathrm{R}} \mathrm{N}^{\mathrm{R}} \mathrm{P}^{\mathrm{R}}\right)$ followed by reduction with excess zinc powder (Scheme 20, top). In 
contrast, complex 71 was isolated using a one pot synthetic protocol. Furthermore, using 2 equiv of $\mathrm{P}^{\mathrm{R}} \mathrm{N}^{\mathrm{R}} \mathrm{P}^{\mathrm{R}}$ ligand and $\mathrm{VCl}_{3}(\mathrm{THF})_{3}$ under reducing conditions produces the octahedral complexes $\mathrm{VCl}_{2}\left(\mathrm{P}^{\mathrm{R}} \mathrm{N}^{\mathrm{R}} \mathrm{P}^{\mathrm{R}}\right)_{2}$ (72-73) (Scheme 20, bottom). In all cases, the complexes are paramagnetic and all but $\mathbf{7 2}$ were structurally characterized. Despite the complexes being coordinatively unsaturated 15 -electron compounds, the PNP and $\mathrm{P}_{2} \mathrm{~N}_{2}$ ligands coordinate in a $\kappa^{2}$ binding mode, this was particularly surprising for complex 71 in which the boat-chair conformation of the $\mathrm{P}_{2} \mathrm{~N}_{2}$ ligand can adopt a geometry that positions the amine group in close proximity to the metal center.

There electrochemical behavior of $68,69,71$ and 73 was also investigated $\left(25^{\circ} \mathrm{C}\right.$, THF). Complexes 68 and 69 exhibit reversible $\mathrm{V}^{\mathrm{III} / \mathrm{II}}$ redox waves at -0.85 and $-0.81 \mathrm{~V}$, respectively; compounds 71 and 73 exhibit quasi-reversible $\mathrm{V}^{\mathrm{III} / \mathrm{II}}$ waves at -0.85 and $-0.87 \mathrm{~V}$, respectively [98]. These vanadium complexes are the first examples of complexes containing pendant amines with a group 5 metal, and represent possible entry points for $\mathrm{N}_{2}$ fixation chemistry, as well as systems for electrocatalytic $\mathrm{H}_{2}$ oxidation.

\section{Conclusions and Outlook}

With the specific objective of controlling proton transfers for the multi-proton, multielectron reduction of $\mathrm{N}_{2}$ to $\mathrm{N}_{2} \mathrm{H}_{4}$ and/or $\mathrm{NH}_{3}$, these studies have advanced our understanding of how pendant amine bases in second coordination sphere of transition metal dinitrogen complexes can affect reactivity with protons. Indeed, we have demonstrated that phosphine ligands with pendant amine bases can support a variety of inexpensive transition metal dinitrogen complexes. In particular, the synthesis, characterization, and reduction of $\mathrm{N}_{2}$ by phosphine-supported $\mathrm{Cr}-\mathrm{N}_{2}$ 
complexes represents an emergent area where significant advancements by our group have been made. Reactivity studies of the $\mathrm{Cr}-\mathrm{N}_{2}$ complexes trans-[Cr$\left.\left(\mathrm{N}_{2}\right)_{2}\left(\mathrm{P}_{4} \mathrm{Ph}_{4} \mathrm{Bn}_{4}\right)\right]$ (6) and cis$\left[\mathrm{Cr}\left(\mathrm{N}_{2}\right)_{2}\left(\mathrm{P}^{\mathrm{Et}} \mathrm{N}^{\mathrm{R}} \mathrm{P}^{\mathrm{Et}}\right)_{2}\right](\mathrm{R}=$ 2,6-difluorobenzyl) [66] with triflic acid at low temperatures produced hydrazine as the main $\mathrm{N}_{2}$ reduction product, while ammonia was formed in lesser amounts. The addition of triflic acid at low temperature to $\mathrm{Cr}\left(\mathrm{N}_{2}\right)(\mathrm{dmpe})\left(\mathrm{P}^{\mathrm{Ph}_{3} \mathrm{~N}^{\mathrm{Bn}}}{ }_{3}\right)(\mathbf{8})$ produced only trace amounts of ammonia.

Broadly, the acid reactivity studies of Mo and $\mathrm{W}-\mathrm{N}_{2}$ complexes containing PNP ligands with amines in the ligand backbone revealed that the amines may be responsible for facilitating intramolecular proton movement to the thermodynamically favored metal center, compared to analogous complexes without the amines that resulted in protonation exclusively at the $\mathrm{N}_{2}$ ligand. It is clear that a judicious choice of metal, as well as the steric and electronic properties of the pendant amine, must be considered to control the site of protonation and ultimately form $\mathrm{M}-\mathrm{N}_{\mathrm{x}} \mathrm{H}_{\mathrm{y}}$ intermediates along the $\mathrm{N}_{2}$ reduction pathway. Our recent progress in ligand design of Mo- $\mathrm{N}_{2}$ complexes incorporating pendant amines as the terminal substituents on the phosphines ( $\mathrm{P}^{\mathrm{E}} \mathrm{P}^{\mathrm{NRR}}$ ' ligand) underscores the importance of these variables as selective protonation at the metal, pendant amine, or $\mathrm{N}_{2}$ ligand was achieved using this ligand platform.

An Fe(II) system containing dmpm and $\mathrm{P}^{\mathrm{Et}} \mathrm{N}^{\mathrm{Me}} \mathrm{P}^{\mathrm{Et}}$ ligands was employed to examine $\mathrm{N}_{2}$, $\mathrm{H}_{2}$, and $\mathrm{NH}_{3}$ ligand binding to the metal. Protonation studies of provided insights on the effect of amine protonation on redox potential of the $\mathrm{Fe}-\mathrm{N}_{2}$ complex and $\mathrm{N}_{2}$ stretching frequency, resulting in the onset of the $\mathrm{Fe}^{\mathrm{II} / \mathrm{I}}$ reduction wave to shift by $+0.33 \mathrm{~V}$ and the $\mathrm{N}_{2}$ stretching frequency to increase by $25 \mathrm{~cm}^{-1}$. Access to $\mathrm{Fe}(0)-\mathrm{N}_{2}$ complexes was not achieved with the $\mathrm{P}^{\mathrm{E}} \mathrm{N}^{\mathrm{Me}} \mathrm{P}$ t ligand platform due to $\mathrm{C}-\mathrm{H}$ activation at the PNP methylene groups affording 
$\mathrm{HFe}\left(\mathrm{Et}_{2} \mathrm{PC}(\mathrm{H}) \mathrm{N}(\mathrm{Me}) \mathrm{CH}_{2} \mathrm{PEt}_{2}\right)\left(\mathrm{P}^{\mathrm{Et}} \mathrm{N}^{\mathrm{Me}} \mathrm{P}^{\mathrm{Et}}\right)$ (60). Formation of $\mathbf{6 0}$ was energetically preferred over $\mathrm{N}_{2}$ binding, however, acid addition showed that one equiv of protons resulted in $\mathrm{N}_{2}$ binding in $c i s-\left[\mathrm{Fe}(\mathrm{H})\left(\mathrm{N}_{2}\right)\left(\mathrm{P}^{\mathrm{E} t} \mathrm{~N}^{\mathrm{Me}} \mathrm{P}^{\mathrm{Et}}\right)_{2}\right]^{+}(\mathbf{6 1})$, which can be protonated further at both pendant amine sites to form a tricationic $\mathrm{HFe}(\mathrm{II})-\mathrm{N}_{2}$ complex. Reactions with $\mathrm{Cp}_{2} \mathrm{Co}$ resulted in $\mathrm{N}_{2}$ loss, $\mathrm{H}_{2}$ formation, and $\mathrm{N}_{2}$ uptake in the cooresponding $\mathrm{HFe}(\mathrm{II})-\mathrm{N}_{2}$ complex of with $1+$ lower overall charge.

With the goal of preparing well-defined transition metal complexes capable of catalyzing the electrochemical conversion of dinitrogen to ammonia and/or hydrazine with protons and electrons in mind, a continued effort to match the $\mathrm{p} K_{\mathrm{a}}$ of a pendant base and the dinitrogen ligand(s) by utilizing experimental and computational methods to obtain $\mathrm{N}-\mathrm{H}$ bond energies, will be essential in the design of molecular complexes for $\mathrm{N}_{2}$ reduction. In this regard, present efforts in our group are focused on synthesizing metal-dinitrogen complexes with multi-dentate phosphine ligands containing pendant amines. The studies described in this review represent a foundation for further optimization in ligand design to test the reactivity of these new systems with exogenous proton and electron sources, and develop molecular electrocatalytic systems for $\mathrm{N}_{2}$ reduction. In addition, we aim to further exploit second coordination sphere pendant amine groups, for the reverse reaction; the six-proton, six-electron electrochemical oxidation of ammonia to $\mathrm{N}_{2}$. Efforts are currently underway to utilize the basicity and close proximity of amine groups to coordinated $\mathrm{NH}_{3}$ ligands to facilitate the cleavage of $\mathrm{N}-\mathrm{H}$ bonds. This work will complement the $\mathrm{N}_{2}$ reduction studies by providing thermodynamic information on $\mathrm{N}-\mathrm{H}$ bond energies that will be critical to aid catalyst design, and will further our ability to predict and control proton movement for making or breaking $\mathrm{N}-\mathrm{H}$ bonds. 


\section{Acknowledgments}

MTM is thankful to the current and former postdoctoral researchers, coworkers in the Center for Molecular Electrocatalysis (CME), and members of the Catalysis Science Group at PNNL that contributed experimentally and intellectually to the development of the transition metal dinitrogen complexes described in this review: Shentan Chen, Jonathan Darmon, Jonathan Egbert, Amy Groves, Zachariah Heiden, Liezel Labios, Molly O’Hagan, Aaron Pierpont, Roger Rousseau, Elizabeth Tyson, Charlie Weiss, Eric Walter, and Eric Wiedner. MTM expresses a special debt of gratitude to Morris Bullock, Dan DuBois, Aaron Appel, and Monte Helm for their scientific leadership and mentorship in the CME. Thanks to our collaborators William Dougherty, Nicholas Piro, and Scott Kassel for performing X-ray crystallography experiments. This work was supported as part of the Center for Molecular Electrocatalysis, an Energy Frontier Research Center funded by the U.S. Department of Energy (U.S. DOE), Office of Science, Office of Basic Energy Sciences. EPR studies on Fe were performed using EMSL, a national scientific user facility sponsored by the DOE's Office of Biological and Environmental Research and located at PNNL. Computational resources were provided by the National Energy Research Scientific Computing Center (NERSC) at Lawrence Berkeley National Laboratory. Pacific Northwest National Laboratory is operated by Battelle for the U.S. DOE.

\section{References}

[1] N.S. Lewis, D.G. Nocera, Proc. Natl. Acad. Sci. U.S.A. 103 (2006) 15729-15735. 
[2] "Catalysis without Precious Metals," R.M. Bullock, Ed. Wiley-VCH, Weinheim, 2010.

[3] F. Schüth, R. Palkovits, R. Schlögl, D.S. Su, Energy Environ. Sci. 5 (2012) 6278-6289.

[4] W.I. David, J.W. Makepeace, S.K. Callear, H.M. Hunter, J.D. Taylor, T.J. Wood, M.O. Jones, J. Am. Chem. Soc. 136 (2014) 13082-13085.

[5] N.V. Rees, R.G. Compton, Energy Environ. Sci. 4 (2011) 1255-1260.

[6] V.S. Thoi, Y. Sun, J.R. Long, C.J. Chang, Chem. Soc. Rev 42 (2013) 2388-2400.

[7] D.G. Nocera, Inorg. Chem. 48 (2009) 10001-10017.

[8] T.R. Cook, D.K. Dogutan, S.Y. Reece, Y. Surendranath, T.S. Teets, D.G. Nocera, Chem. Rev. 110 (2010) 6474-6502.

[9] B.M. Hoffman, D.R. Dean, L.C. Seefeldt, Acc. Chem. Res. 42 (2009) 609-619.

[10] D. Lukoyanov, Z.-Y. Yang, B.M. Barney, D.R. Dean, L.C. Seefeldt, B.M. Hoffman, Proc. Natl. Acad. Sci. U. S. A. 109 (2012) 5583-5587.

[11] B.M. Hoffman, D. Lukoyanov, D.R. Dean, L.C. Seefeldt, Acc. Chem. Res. 46 (2013) 587-595.

[12] B.M. Hoffman, D. Lukoyanov, Z.Y. Yang, D.R. Dean, L.C. Seefeldt, Chem. Rev. 114 (2014) 4041-4062.

[13] J.B. Howard, D.C. Rees, Chem. Rev. 96 (1996) 2965-2982.

[14] V. Smil, Enriching the Earth: Fritz Haber, Carl Bosch, and the Transformation of World Food Production, MIT Press, Cambridge, MA, 2001.

[15] R. Schlogl, Handbook of Heterogeneous Catalysis, 2nd ed., Wiley-VCH, Weinheim, 2008.

[16] R. Schlogl, Angew. Chem. Int. Ed. 42 (2003) 2004-2008.

[17] D.L. DuBois, Inorg. Chem. 53 (2014) 3935-3960.

[18] Y. Nicolet, J.C. Fontecilla-Camps, J. Biol. Chem. 287 (2012) 13532-13540.

[19] C.J. Curtis, A. Miedaner, R. Ciancanelli, W.W. Ellis, B.C. Noll, M. Rakowski DuBois, D.L. DuBois, Inorg. Chem. 42 (2003) 216-227.

[20] J. Yang, S. Chen, W.G. Dougherty, W.S. Kassel, R.M. Bullock, D. DuBois, S. Raugei, R. Rousseau, M. Dupuis, M. Rakowski DuBois, Chem. Commun. 46 (2010) 8618-8620.

[21] J.Y. Yang, S.E. Smith, T. Liu, W.G. Dougherty, W.A. Hoffert, W.S. Kassel, M. Rakowski DuBois, D.L. DuBois, R.M. Bullock, J. Am. Chem. Soc. 135 (2013) 9700-9712.

[22] D.V. Yandulov, R.R. Schrock, Science 301 (2003) 76-78.

[23] K. Arashiba, Y. Miyake, Y. Nishibayashi, Nat. Chem. 3 (2011) 120-125.

[24] J.S. Anderson, J. Rittle, J.C. Peters, Nature 501 (2013) 84-87.

[25] G. Ung, J.C. Peters, Angew. Chem. Int. Ed. 54 (2014) 532-535.

[26] S.E. Creutz, J.C. Peters, J. Am. Chem. Soc. 136 (2014) 1105-1115.

[27] K. Arashiba, E. Kinoshita, S. Kuriyama, A. Eizawa, K. Nakajima, H. Tanaka, K. Yoshizawa, Y. Nishibayashi, J. Am. Chem. Soc. 137 (2015) 5666-5669.

[28] Y. Nishibayashi, Inorg. Chem. 54 (2015) 9234-9247.

[29] N. Khoenkhoen, B. de Bruin, J.N.H. Reek, W.I. Dzik, Eur. J. Inorg. Chem. 2015 (2015) 567-598.

[30] Y. Tanabe, Y. Nishibayashi, Coord. Chem. Rev. 257 (2013) 2551-2564.

[31] K.C. MacLeod, P.L. Holland, Nat. Chem. 5 (2013) 559-565.

[32] S. Hinrichsen, H. Broda, C. Gradert, L. Soncksen, F. Tuczek, Annu. Rep. Prog. Chem., Sect. A 108 (2012) 17-47. 
[33] J.L. Crossland, D.R. Tyler, Coord. Chem. Rev. 254 (2010) 1883-1894.

[34] N. Hazari, Chem. Soc. Rev. 39 (2010) 4044-4056.

[35] J. Chatt, J.R. Dilworth, R.L. Richards, Chem. Rev. 78 (1978) 589-625.

[36] M. Hidai, Y. Mizobe, Chem. Rev. 95 (1995) 1115-1133.

[37] M. Hidai, Coord. Chem. Rev. 186 (1999) 99-108.

[38] B.A. MacKay, M.D. Fryzuk, Chem. Rev. 104 (2004) 385-401.

[39] H. Broda, S. Hinrichsen, F. Tuczek, Coord. Chem. Rev. 257 (2013) 587-598.

[40] L.A. Berben, S.A. Kozimor, Inorg. Chem. 47 (2008) 4639-4647.

[41] I. Vidyaratne, J. Scott, S. Gambarotta, P.H.M. Budzelaar, Inorg. Chem. 46 (2007) 7040-7049.

[42] P. Sobota, B. Jezowska-Trzebiatowska, J. Organomet. Chem. 131 (1977) 341-345.

[43] H.H. Karsch, Angew. Chem. Int. Ed. 16 (1977) 56-57.

[44] G.S. Girolami, J.E. Salt, G. Wilkinson, M. Thornton-Pett, M.B. Hursthouse, J . Am. Chem. Soc. 105 (1983) 5954-5956.

[45] J.E. Salt, G.S. Girolami, G. Wilkinson, M. Motevalli, M. Thornton-Pett, M.B. Hursthouse, J. Chem. Soc. Dalton Trans. (1985) 685-692.

[46] J.E. Salt, G. Wilkinson, M. Motevalli, M.B. Hursthouse, J. Chem. Soc. Dalton Trans. (1986) 1141-1154.

[47] M.T. Mock, S. Chen, R. Rousseau, M.J. O'Hagan, W.G. Dougherty, W.S. Kassel, D.L. DuBois, R.M. Bullock, Chem. Commun. 47 (2011) 12212-12214.

[48] E.B. Hulley, M.L. Helm, R.M. Bullock, Chem. Sci. 5 (2014) 4729-4741.

[49] S. Zhang, R.M. Bullock, Inorg. Chem. 54 (2015) 6397-6409.

[50] Revised ${ }^{15} \mathrm{~N}$ chemical shift values for $\mathbf{2}$, correcting the original report.

[51] G.S. Girolami, G. Wilkinson, A.M.R. Galas, M. Thorton-Pett, M.B. Hursthouse, J. Chem. Soc. Dalton Trans. (1985) 1339-1348.

[52] G. Ricci, A. Forni, A. Boglia, M. Sonzogni, Organometallics 23 (2004) 3727-3732.

[53] M.T. Mock, S. Chen, M. O'Hagan, R. Rousseau, W.G. Dougherty, W.S. Kassel, R.M. Bullock, J. Am. Chem. Soc. 135 (2013) 11493-11496.

[54] J.R. Dilworth, S. Donovan-Mtunzi, C.T. Kan, R.L. Richards, J. Mason, Inorg. Chim. Acta 53 (1981) L161-L162.

[55] J. Chatt, R.L. Richards, J. Organomet. Chem. 239 (1982) 65-77.

[56] J. Chatt, A.J. Pearman, R.L. Richards, J. Chem. Soc. Dalton Trans. (1976) 1520-1524.

[57] M.T. Mock, A.W. Pierpont, J.D. Egbert, M. O'Hagan, S. Chen, R.M. Bullock, W.G. Dougherty, W.S. Kassel, R. Rousseau, Inorg. Chem. 54 (2015) 4827-4839.

[58] J. Krahmer, H. Broda, C. Näther, G. Peters, W. Thimm, F. Tuczek, Eur. J. Inorg. Chem. 2011 (2011) 4377-4386.

[59] K. Klatt, G. Stephan, G. Peters, F. Tuczek, Inorg. Chem. 47 (2008) 6541-6550.

[60] G.C. Stephan, G. Peters, N. Lehnert, C.M. Habeck, C. Näther, F. Tuczek, Can. J. Chem. 83 (2005) 385-402.

[61] L. Söncksen, C. Gradert, J. Krahmer, C. Nather, F. Tuczek, Inorg. Chem. 52 (2013) 6576-6589.

[62] H. Broda, S. Hinrichsen, J. Krahmer, C. Nather, F. Tuczek, Dalton Trans. 43 (2014) 2007-2012. 
[63] H. Broda, J. Krahmer, F. Tuczek, Eur. J. Inorg. Chem. 2014 (2014) 3564-3571.

[64] D.F. Shriver, Acc. Chem. Res. 3 (1970) 231-238.

[65] F. Tuczek, K.H. Horn, N. Lehnert, Coord. Chem. Rev. 245 (2003) 107-120.

[66] Note added during revisions: We recently reported the spectroscopic characteristics and acid reactivity of an isostructural series of Group $6 \mathrm{~N}_{2}$ complexes, cis-[M( $\left.\left.\mathrm{N}_{2}\right)_{2}\left(\mathrm{P}^{\mathrm{Et}} \mathrm{N}^{\mathrm{R}} \mathrm{P}^{\mathrm{Et}}\right)_{2}\right](\mathrm{M}=\mathrm{Cr}$, Mo, W; $\mathrm{R}=2$,6-difluorobenzyl). Protonolysis experiments showed that only $\mathrm{Cr}$ produced $\mathrm{N}_{2} \mathrm{H}_{5}{ }^{+}$ and $\mathrm{NH}_{4}{ }^{+}$from reduction of the $\mathrm{N}_{2}$ ligands: J. D. Egbert, M. O'Hagan, E. S. Wiedner, R. M. Bullock, N. A. Piro, W. S. Kassel, M. T. Mock, Chem. Commun. (2016) DOI: 10.1039/ c6cc03449g.

[67] S. Kuriyama, K. Arashiba, K. Nakajima, H. Tanaka, N. Kamaru, K. Yoshizawa, Y. Nishibayashi, J. Am. Chem. Soc. 136 (2014) 9719-9731.

[68] J.R. Dilworth, R. Richards, Inorg. Synth. 28 (2007) 33-43.

[69] C.J. Weiss, A.N. Groves, M.T. Mock, W.G. Dougherty, W.S. Kassel, M.L. Helm, D.L. DuBois, R.M. Bullock, Dalton Trans. 41 (2012) 4517-4529.

[70] W. Hussain, G.J. Leigh, H.M. Ali, C.J. Pickett, D.A. Rankin, J. Chem. Soc., Dalton Trans. (1984) 1703-1708.

[71] L.A. Labios, C.J. Weiss, J.D. Egbert, S. Lense, R.M. Bullock, W.G. Dougherty, W.S. Kassel, M.T. Mock, Z. Anorg. Allg. Chem. 641 (2015) 105-117.

[72] G.C. Stephan, C. Nather, C. Sivasankar, F. Tuczek, Inorg. Chim. Acta 361 (2008) 10081019.

[73] G. Stephan, C. Nather, F. Tuczek, Acta Crystallogr., Sect. E: Struct. Rep. Online E64 (2008) m629.

[74] M. Yuki, Y. Miyake, Y. Nishibayashi, I. Wakiji, M. Hidai, Organometallics 27 (2008) 3947-3953.

[75] M. Yuki, Y. Miyake, Y. Nishibayashi, Organometallics 28 (2009) 5821-5827.

[76] M. Hidai, T. Kodama, M. Sato, M. Harakawa, Y. Uchida, Inorg. Chem. 15 (1976) 2694-2697.

[77] T.A. George, L. Ma, S.N. Shailh, R.C. Tisdale, J. Zubieta, Inorg. Chem. 29 (1990) 4789-4796.

[78] K. Gebreyes, J. Zubieta, T.A. George, L.M. Koczon, R.C. Tisdale, Inorg. Chem. 25 (1986) 405-407.

[79] R.A. Henderson, J. Chem. Soc., Dalton Trans. (1984) 2259-2163.

[80] L.A. Labios, Z.M. Heiden, M.T. Mock, Inorg. Chem. 54 (2015) 4409-4422.

[81] G.C. Stephan, C. Näther, C. Sivasankar, F. Tuczek, Inorg. Chim. Acta 361 (2008) 1008-1019.

[82] C.J. Weiss, J.D. Egbert, S. Chen, M.L. Helm, R.M. Bullock, M.T. Mock, Organometallics 33 (2014) 2189-2200.

[83] A.L. Chaney, E.P. Marbach, Clin. Chem. 8 (1962) 130-132.

[84] M.W. Weatherburn, Anal. Chem. 39 (1967) 971-974.

[85] S.F. McWilliams, P.L. Holland, Acc. Chem. Res. 48 (2015) 2059-2065.

[86] J.S. Anderson, G.E. Cutsail, 3rd, J. Rittle, B.A. Connor, W.A. Gunderson, L. Zhang, B.M. Hoffman, J.C. Peters, J. Am. Chem. Soc. 137 (2015) 7803-7809.

[87] J.D. Gilbertson, N.K. Szymczak, D.R. Tyler, J. Am. Chem. Soc. 127 (2005) 10184-10185. 
[88] C.G. Balesdent, J.L. Crossland, D.T. Regan, C.T. Lopez, D.R. Tyler, Inorg. Chem. 52 (2013) 14178-14187.

[89] L.D. Field, N. Hazari, H.L. Li, Inorg. Chem. 54 (2015) 4768-4776.

[90] Z.M. Heiden, S. Chen, M.T. Mock, W.G. Dougherty, W.S. Kassel, R. Rousseau, R.M. Bullock, Inorg. Chem. 52 (2013) 4026-4039.

[91] R.M. Henry, R.K. Shoemaker, R.H. Newell, G.M. Jacobsen, D.L. DuBois, M.R. DuBois, Organometallics 24 (2005) 2481-2491.

[92] Z.M. Heiden, S. Chen, L.A. Labios, R.M. Bullock, E.D. Walter, E.L. Tyson, M.T. Mock, Organometallics 33 (2014) 1333-1336.

[93] Z.Y. Yang, N. Khadka, D. Lukoyanov, B.M. Hoffman, D.R. Dean, L.C. Seefeldt, Proc. Natl. Acad. Sci. U. S. A. 110 (2013) 16327-16332.

[94] G. Liu, X. Liang, A. Meetsma, B. Hessen, Dalton Trans. 39 (2010) 7891-7893.

[95] C. Woitha, D. Rehder, Angew. Chem. Int. Ed. 29 (1990) 1438-1440.

[96] D. Rehder, C. Woitha, W. Priebsch, H. Gailus, J. Chem. Soc. Chem. Commun. (1992) 364-365.

[97] H. Gailus, C. Woitha, D. Rehder, J. Chem. Soc. Dalton Trans. (1994) 3471-3477.

[98] J.D. Egbert, L.A. Labios, J.M. Darmon, N.A. Piro, W. Scott Kassel, M.T. Mock, Eur. J. Inorg. Chem 2016 (2016) 1293-1299.

[99] J. Nieman, J.H. Teuben, J.C. Huffman, K.G. Caulton, J. Organomet. Chem. 255 (1983) 193-204. 